Article

\title{
Assessment of Mechanical Properties and Structural Morphology of Alkali-Activated Mortars with Industrial Waste Materials
}

\author{
Iman Faridmehr ${ }^{1}$ (D), Chiara Bedon ${ }^{2, *(D)}$, Ghasan Fahim Huseien ${ }^{3}$, Mehdi Nikoo ${ }^{4}(\mathbb{D}$ \\ and Mohammad Hajmohammadian Baghban ${ }^{5}$ (D)
}

check for updates

Citation: Faridmehr, I.; Bedon, C.; Huseien, G.F.; Nikoo, M.; Baghban, M.H. Assessment of Mechanical Properties and Structural Morphology of Alkali-Activated Mortars with Industrial Waste Materials. Sustainability 2021, 13, 2062. https://doi.org/10.3390/ su13042062

Academic Editor: José Ignacio Alvarez

Received: 18 January 2021

Accepted: 10 February 2021

Published: 14 February 2021

Publisher's Note: MDPI stays neutral with regard to jurisdictional claims in published maps and institutional affiliations.

Copyright: (c) 2021 by the authors. Licensee MDPI, Basel, Switzerland. This article is an open access article distributed under the terms and conditions of the Creative Commons Attribution (CC BY) license (https:/ / creativecommons.org/licenses/by/ $4.0 /)$.
1 Institute of Architecture and Construction, South Ural State University, Lenin Prospect 76, 454080 Chelyabinsk, Russia; faridmekhri@susu.ru

2 Department of Engineering and Architecture, University of Trieste, Via Alfonso Valerio 6/1, 34127 Trieste, Italy

3 Department of Building, School of Design and Environment, National University of Singapore, Singapore 117566, Singapore; eng.gassan@yahoo.com

4 Young Researchers and Elite Club, Ahvaz Branch, Islamic Azad University, Ahvaz 61349-37333, Iran; m.nikoo@iauahvaz.ac.ir

5 Department of Manufacturing and Civil Engineering, Norwegian University of Science and Technology (NTNU), 2815 Gjøvik, Norway; mohammad.baghban@ntnu.no

* Correspondence: chiara.bedon@dia.units.it; Tel.: +39-040-558-3837

\begin{abstract}
Alkali-activated products composed of industrial waste materials have shown promising environmentally friendly features with appropriate strength and durability. This study explores the mechanical properties and structural morphology of ternary blended alkali-activated mortars composed of industrial waste materials, including fly ash (FA), palm oil fly ash (POFA), waste ceramic powder (WCP), and granulated blast-furnace slag (GBFS). The effect on the mechanical properties of the $\mathrm{Al}_{2} \mathrm{O}_{3}, \mathrm{SiO}_{2}$, and $\mathrm{CaO}$ content of each binder is investigated in 42 engineered alkali-activated mixes (AAMs). The AAMs structural morphology is first explored with the aid of X-ray diffraction, scanning electron microscopy, and Fourier-transform infrared spectroscopy measurements. Furthermore, three different algorithms are used to predict the AAMs mechanical properties. Both an optimized artificial neural network (ANN) combined with a metaheuristic Krill Herd algorithm (KHA-ANN) and an ANN-combined genetic algorithm (GA-ANN) are developed and compared with a multiple linear regression (MLR) model. The structural morphology tests confirm that the high GBFS volume in AAMs results in a high volume of hydration products and significantly improves the final mechanical properties. However, increasing POFA and WCP percentage in AAMs manifests in the rise of unreacted silicate and reduces C-S-H products that negatively affect the observed mechanical properties. Meanwhile, the mechanical features in AAMs with high-volume FA are significantly dependent on the GBFS percentage in the binder mass. It is also shown that the proposed KHA-ANN model offers satisfactory results of mechanical property predictions for AAMs, with higher accuracy than the GA-ANN or MLR methods. The final weight and bias values given by the model suggest that the KHA-ANN method can be efficiently used to design AAMs with targeted mechanical features and desired amounts of waste consumption.
\end{abstract}

Keywords: fly ash; granulated blast-furnace slag; palm oil fly ash; ordinary Portland cement; recycled ceramics; green mortar; alkali-activated mix design; compressive strength; embodied energy; $\mathrm{CO}_{2}$ emission

\section{Introduction}

There is an environmental concern worldwide regarding the production of ordinary Portland cement (OPC), as it is widely use in the construction sector. It is commonly accepted that OPC manufacturing causes serious pollution issues, including a considerable 
amount of $\mathrm{CO}_{2}$ emissions. The majority of annually produced concrete (10 billion metric tons of concrete) contains OPC [1]. Every ton of OPC generates approximately one ton of $\mathrm{CO}_{2}$, and around $7 \%$ of all the global $\mathrm{CO}_{2}$ emissions are ascribed to OPC production and its corresponding raw material extraction process [2]. It was also estimated that OPC manufacturing would quadruple over the next three decades, which is expected to lead to extensive environmental impacts [3]. To address this concern, using industrial by-products (green concrete philosophy), instead of raw material extraction in conventional concrete, is recognized as a practical solution for a sustainable and cleaner concrete production. Meanwhile, the disposal of industrial waste materials is associated with undesirable ecological impacts. In contrast, their recycling largely contributes to sustainable design, saving natural resources and preventing waste dumping into landfills. The application of industrial wastes with environmentally friendly (i.e., low energy consumption and low $\mathrm{CO}_{2}$ emission) and inexpensive properties for partial or full replacement of OPC in concrete have attracted the attention of many researchers [4-7]. Allalouex et al. [8] explored the effects of calcined halloysite nano-clay (CHNC) on the physico-mechanical properties and microstructure of high volume slag (HVS) cement mortar. The study in [9] investigated the feasibility of novel industrial waste-co-fired blended ash (CBA) in the development of alkali-activated masonry mortar and reinforced alkali-activated mortar. The design and preparation of Mater-Bi/halloysite nanocomposite materials that could be employed as bioplastics alternative to the petroleum derived products was investigated by Lisuzzo et al. [10]. A novel green protocol for the consolidation and protection of waterlogged archeological woods with wax microparticles has been designed in [11].

This research considers four different industrial waste materials, granulated blastfurnace slag (GBFS), palm oil fly ash (POFA), fly ash (FA), and waste ceramic powder (WCP) in ternary blended alkali-activated mortars. FA, burnt coal by-product, is among the most attractive industrial wastes for producing AAMs because of several unique properties, such as high levels of $\mathrm{SiO}_{2}$ and $\mathrm{Al}_{2} \mathrm{O}_{3}$, low cost and embodied energy, and availability at a large scale in many countries. Ogawa et al. [12] investigated the contribution of fly ash to the compressive strength development of mortars cured at different temperatures on the basis of the cementing efficiency factor, they concluded that this factor is significantly affected by the curing temperature. An experimental study on the stress-strain characteristics of alkali-activated slag (AAS) and alkali-activated class C fly ash (FAC) mortars subjected to axial compression was presented in [13]. The authors concluded that the brittleness index estimated from the stress-strain characteristics increases with an increase of activator concentration. In addition, Alkali-activated slag mortar displays highly brittle behaviour marked by no softening behaviour followed by sudden and total failure.

POFA is a by-product mostly produced by various agriculture industries (by burning agricultural waste) in Southeast Asia countries. There is no market value for POFA, and its application is typically limited to landfilling in lagoons and ponds associated with significant environmental pollution. POFA is classified as a pozzolanic substance that is rich in silica content. Accordingly, such an abundant agricultural waste can be used as a partial substitute for OPC, or as a concrete binder to improve strength and durability. The use of an optimum level of POFA, ground granulated blast furnace slag (GGBS), and low calcium FA with manufactured sand (M-sand) to produce geopolymer mortar was investigated by Islam et al. [14]. They concluded that the increase in the POFA content beyond $30 \%$ reduces the compressive strength. In another study, the effects of exposing POFA/FA-based geopolymer mortar to elevated temperatures at an early stage in terms of microstructural and compressive strength was investigated in [15]. They concluded that that replacement of the $0-100 \%$ of POFA in FA-based geopolymer mortar expedites the start of micro-pore formation, due to exposure to high temperatures and shifts the strength peak from $300{ }^{\circ} \mathrm{C}$ to $500{ }^{\circ} \mathrm{C}$.

Furthermore, WCP has high durability to harsh environmental (sulfuric acid or sulfate) conditions. Generally, this material waste has mainly been recycled as a filler for applications such as gardening and tartan floors. To follow a sustainable design approach, several 
studies proposed the application of ceramic waste in concrete and mortar [16]. The main drawback of using ceramic waste (fine or coarse aggregates) as a replacement of limestone aggregates is its extensive water absorption. Therefore, the durability of such a mix may turn out to be its major deficiency. Harsh environmental agents such as carbonation, chloride, and deleterious salts may easily penetrate the concrete and negatively influence its mechanical properties. Samadi et al. [17] investigated the long-term performance, mechanical properties, and durability of a mortar comprising ceramic waste as supplementary cementitious material and ceramic particles as fine aggregates. In this study, the structure morphology and thermal traits of the designed mixes were characterized using scanning electron microscopy (SEM), thermogravimetric analysis (TGA), differential thermal analysis (DTA), X-Ray Diffraction (XRD), and Fourier-transform infrared spectroscopy (FTIR) measurements. Mechanical and microstructural properties of mortars incorporating ceramic waste powder exposed to the hydrochloric acid solution was investigated in [18]. GBFS (a by-product of iron and steel production) has high $\mathrm{SiO}_{2}$, and $\mathrm{CaO}$ content levels in GBFS provide mechanical properties similar to OPC. It can be used as an OPC replacement producing calcium silicate hydrates (C-S-H), which are strength-enhancing compounds that improve the concrete's strength, durability, and appearance. The effect of granulated blast furnace slag on the self-healing capability of mortar incorporating crystalline admixture was investigated by Li et al. [19]. The results of this study indicated that the mortar with crystalline admixture and $10 \mathrm{wt} \%$ GBFS has the highest self-healing capability, and the healing product is mainly composed of calcium carbonate.

Several researchers proposed the consumption of industrial waste materials in AAM designs as a sustainable substitute for OPC [20-22]. However, limited research has been done about the mechanical properties of ternary blended alkali-activated mortars composed of industrial waste materials. In this paper, the mechanical properties of zero cement binder with ternary blended AAMs composed of industrial waste materials are investigated using experimental tests at different ages (1, 3, 7, and 28 days of curing). The effects of the $\mathrm{SiO}_{2}, \mathrm{CaO}$, and $\mathrm{Al}_{2} \mathrm{O}_{3}$ contents of each binder mass on mechanical properties are investigated using 42 engineered alkali-activated mixes (AAMs). The structural morphology of AAMs is also investigated by the aid of X-ray diffraction (XRD), scanning electron microscopy (SEM), and Fourier-transform infrared spectroscopy (FTIR) measurements. Furthermore, an optimized artificial neural network (ANN) combined with a metaheuristic Krill Herd algorithm (KHA-ANN) and an ANN-combined genetic algorithm (GA-ANN) are developed and compared with a multiple linear regression (MLR) model. From the three different models, the comparative analysis of collected predictions of mechanical properties for the studied AAMs shows the potential of the KHA-ANN model.

\section{Materials and Test Methods}

\subsection{Material Properties of Industrial Wastes}

With the aid of the X-ray fluorescence spectroscopy (XRF) test, the chemical compositions of the studied waste materials were determined, as shown in Table 1. It was revealed that the main component in WCP, FA, and POFA was $\mathrm{SiO}_{2}(72.6 \%, 57.2 \%$, and 64.2\%, respectively), while in the GBFS it was $\mathrm{CaO}(51.8 \%) . \mathrm{SiO}_{2}, \mathrm{Al}_{2} \mathrm{O}_{3}$, and $\mathrm{CaO}$ are important oxides throughout the hydration process and production phases of the $\mathrm{C}-(\mathrm{A})-\mathrm{S}-\mathrm{H}$ gels.

However, the low contents of $\mathrm{Al}_{2} \mathrm{O}_{3}$ and $\mathrm{CaO}$ in WCP require adding materials containing high amounts of $\mathrm{Al}_{2} \mathrm{O}_{3}$ (FA) and $\mathrm{CaO}$ (GBFS) to produce high-performance alkali-activated binders. According to ASTM C618-15 [23], FA and WCP are classified as class $\mathrm{F}$ pozzolans, due to the existence (higher than $70 \%$ ) of $\mathrm{SiO}_{2}+\mathrm{Al}_{2} \mathrm{O}_{3}+\mathrm{Fe}_{2} \mathrm{O}_{3}$.

\subsection{Design of AAMs}

Ternary blended AAMs were examined to determine the influence of calcium oxide on the geopolymerization process. Using trial mixes, the optimum values of sodium silicate to sodium hydroxide ratio, sodium hydroxide molarity, binder to aggregate ratio, and alkaline solution to binder ratio were selected as $0.75,4 \mathrm{M}, 1$, and 0.4 , respectively, where 
these values were fixed for all AAMs. Analytical grade sodium silicate solution $\left(\mathrm{Na}_{2} \mathrm{SiO}_{3}\right)$, comprised of $\mathrm{H}_{2} \mathrm{O}(55.80 \mathrm{wt} \%), \mathrm{SiO}_{2}(29.5 \mathrm{wt} \%)$, and $\mathrm{Na}_{2} \mathrm{O}(14.70 \mathrm{wt} \%)$, was used as an alkali activator to prepare the proposed AAMs. The sodium hydroxide $(\mathrm{NH})$ pellet was dissolved in water to make the alkaline solution with $4 \mathrm{M}$ concentration. This solution was first cooled for around $24 \mathrm{~h}$ and then added to sodium silicate (NS) solution in order to make an alkaline activator solution with a modulus ratio $\left(\mathrm{SiO}_{2}\right.$ to $\left.\mathrm{Na}_{2} \mathrm{O}\right)$ of 1.02. This ratio of NS to NH was fixed to 0.75 for all the alkaline mixtures.

Table 1. Physical and chemical features of waste materials.

\begin{tabular}{|c|c|c|c|c|}
\hline Material & GBFS & FA & POFA & WCP \\
\hline \multicolumn{5}{|c|}{ Physical characteristics } \\
\hline Specific gravity & 2.9 & 2.2 & 1.96 & 2.6 \\
\hline $\begin{array}{l}\text { particle size } \\
(\mu \mathrm{m})\end{array}$ & 12.8 & 10 & 8.2 & 35 \\
\hline \multicolumn{5}{|c|}{ Chemical composition (\% mass) } \\
\hline $\mathrm{SiO}_{2}$ & 30.8 & 57.20 & 64.20 & 72.6 \\
\hline $\mathrm{Al}_{2} \mathrm{O}_{3}$ & 10.9 & 28.81 & 4.25 & 12.6 \\
\hline $\mathrm{Fe}_{2} \mathrm{O}_{3}$ & 0.64 & 3.67 & 3.13 & 0.56 \\
\hline $\mathrm{CaO}$ & 51.8 & 5.16 & 10.20 & 0.02 \\
\hline $\mathrm{MgO}$ & 4.57 & 1.48 & 5.90 & 0.99 \\
\hline $\mathrm{K}_{2} \mathrm{O}$ & 0.36 & 0.94 & 8.64 & 0.03 \\
\hline $\mathrm{Na}_{2} \mathrm{O}$ & 0.45 & 0.08 & 0.10 & 13.5 \\
\hline $\mathrm{SO}_{3}$ & 0.06 & 0.10 & 0.09 & 0.01 \\
\hline $\begin{array}{l}\text { Loss on ignition } \\
\text { (LOI) }\end{array}$ & 0.22 & 0.12 & 1.73 & 0.13 \\
\hline
\end{tabular}

Four ternary blended AAMs were investigated, where at each level, the GBFS percentage as a source of $\mathrm{CaO}$ remained constant to a minimum of $20 \%$ in the replacement process and a maximum of $70 \%$, as presented in Table 2. Using the SEM test, the effects of each industrial waste replacement on the contents of $\mathrm{SiO}_{2}, \mathrm{CaO}$, and $\mathrm{Al}_{2} \mathrm{O}_{3}$ and the AAMs geopolymerization process can be seen.

Table 2. Ternary blended alkali-activated mixes (AAMs) and contents of constituents in each mix design.

\begin{tabular}{|c|c|c|c|c|c|c|}
\hline \multicolumn{7}{|c|}{ High-Volume FA Mix Design } \\
\hline \multirow{2}{*}{ No. } & \multicolumn{3}{|c|}{ Binder (\% Mass) } & \multicolumn{3}{|c|}{ Ratio of Chemical Composition } \\
\hline & FA & GBFS & POFA & $\mathrm{SiO}_{2}: \mathrm{Al}_{2} \mathrm{O}_{3}$ & $\mathrm{CaO}: \mathrm{SiO}_{2}$ & $\mathrm{CaO}: \mathrm{Al}_{2} \mathrm{O}_{3}$ \\
\hline 1 & \multirow{2}{*}{70} & 30 & 0 & 2.10 & 0.39 & 0.82 \\
\hline 2 & & 20 & 10 & 2.31 & 0.28 & 0.66 \\
\hline 3 & \multirow{3}{*}{60} & 40 & 0 & 2.15 & 0.51 & 1.10 \\
\hline 4 & & 30 & 10 & 2.38 & 0.39 & 0.94 \\
\hline 5 & & 20 & 20 & 2.62 & 0.29 & 0.76 \\
\hline 6 & \multirow{4}{*}{50} & 50 & 0 & 2.22 & 0.65 & 1.43 \\
\hline 7 & & 40 & 10 & 2.47 & 0.51 & 1.26 \\
\hline 8 & & 30 & 20 & 2.74 & 0.40 & 1.08 \\
\hline 9 & & 20 & 30 & 3.02 & 0.29 & 0.89 \\
\hline
\end{tabular}


Table 2. Cont.

\begin{tabular}{|c|c|c|c|c|c|c|}
\hline \multicolumn{7}{|c|}{ High-Volume POFA Mix Design } \\
\hline No. & POFA & GBFS & FA & & & \\
\hline 1 & \multirow{2}{*}{70} & 30 & 0 & 8.63 & 0.42 & 3.61 \\
\hline 2 & & 20 & 10 & 7.04 & 0.32 & 2.23 \\
\hline 3 & \multirow{3}{*}{60} & 40 & 0 & 7.32 & 0.53 & 3.86 \\
\hline 4 & & 30 & 10 & 6.13 & 0.41 & 2.54 \\
\hline 5 & & 20 & 20 & 5.33 & 0.31 & 1.66 \\
\hline 6 & \multirow{4}{*}{50} & 50 & 0 & 6.25 & 0.65 & 4.08 \\
\hline 7 & & 40 & 10 & 5.34 & 0.52 & 2.80 \\
\hline 8 & & 30 & 20 & 4.72 & 0.41 & 1.94 \\
\hline 9 & & 20 & 30 & 4.27 & 0.31 & 1.31 \\
\hline \multicolumn{7}{|c|}{ High-Volume GBFS Mix Design } \\
\hline No. & GBFS & FA & POFA & & & \\
\hline 1 & \multirow{4}{*}{70} & 30 & 0 & 2.38 & 0.97 & 2.32 \\
\hline 2 & & 20 & 10 & 2.85 & 0.97 & 2.77 \\
\hline 3 & & 10 & 20 & 3.53 & 0.96 & 3.41 \\
\hline 4 & & 0 & 30 & 4.57 & 0.96 & 4.41 \\
\hline 5 & \multirow{5}{*}{60} & 40 & 0 & 2.29 & 0.80 & 1.83 \\
\hline 6 & & 30 & 10 & 2.69 & 0.80 & 2.15 \\
\hline 7 & & 20 & 20 & 3.25 & 0.79 & 2.59 \\
\hline 8 & & 10 & 30 & 4.06 & 0.79 & 3.23 \\
\hline 9 & & 0 & 40 & 5.35 & 0.79 & 4.25 \\
\hline 10 & \multirow{6}{*}{50} & 50 & 0 & 2.22 & 0.65 & 1.43 \\
\hline 11 & & 40 & 10 & 2.57 & 0.65 & 1.66 \\
\hline 12 & & 30 & 20 & 3.04 & 0.65 & 1.97 \\
\hline 13 & & 20 & 30 & 3.68 & 0.65 & 2.39 \\
\hline 14 & & 10 & 40 & 4.65 & 0.65 & 3.03 \\
\hline 15 & & 0 & 50 & 6.25 & 0.65 & 4.07 \\
\hline \multicolumn{7}{|c|}{ High-Volume WCP Mix Design } \\
\hline No. & WCP & FA & GBFS & & & \\
\hline 1 & \multirow{2}{*}{70} & 0 & 30 & 5.09 & 0.26 & 1.31 \\
\hline 2 & & 10 & 20 & 4.62 & 0.17 & 0.79 \\
\hline 3 & \multirow{3}{*}{60} & 0 & 40 & 4.79 & 0.37 & 1.77 \\
\hline 4 & & 10 & 30 & 4.35 & 0.27 & 1.19 \\
\hline 5 & & 20 & 20 & 4.01 & 0.18 & 0.74 \\
\hline 6 & \multirow{4}{*}{50} & 0 & 50 & 4.48 & 0.50 & 2.24 \\
\hline 7 & & 10 & 40 & 4.08 & 0.39 & 1.59 \\
\hline 8 & & 20 & 30 & 3.77 & 0.29 & 1.09 \\
\hline 9 & & 30 & 20 & 3.53 & 0.20 & 0.70 \\
\hline
\end{tabular}

The essential features of Table 2 can be summarized as follows: 
- For AAMs with a high volume of FA, $\mathrm{CaO}$ content is observed to increase with increasing GBFS content and decreasing FA and POFA contents. However, $\mathrm{Al}_{2} \mathrm{O}_{3}$ content decreases with increasing GBFS and POFA contents and decreasing FA content.

- For AAMs with a high volume of POFA, the reduction in the POFA content leads to progressive reduction of the silicate content. Furthermore, the $\mathrm{Al}_{2} \mathrm{O}_{3}$ content increases when the ratio of GBFS to FA increases, whereas the $\mathrm{CaO}$ content significantly decreases.

- For AAMs with a high volume of GBFS, an increase in the GBFS content leads to an increase in $\mathrm{CaO}$ content. However, by decreasing GBFS content and increasing POFA content, $\mathrm{SiO}_{2}$ content increases.

- For AAMs with a high volume of WCP, finally, an increase in the content of WCP leads to an enhancement of $\mathrm{SiO}_{2}$ content. Additionally, the replacement of WCP by increasing the amount of GBFS results in an increased $\mathrm{CaO}$ content.

\subsection{Experimental Test Procedure}

After preparing the AAMs, the experimental program discussed herein involved the casting process, where the resulting mortar was poured into the molds using the two-layers pouring method. To eliminate air pockets within the mixture, each layer was subjected to vibration for $15 \mathrm{~s}$. After finishing the casting process, the AAMs were cured for $24 \mathrm{~h}$ in an ambient atmosphere (with a temperature $24 \pm 1.5^{\circ} \mathrm{C}$ and a relative humidity of $75 \%$ ). Figure 1 illustrates the typical procedure to obtain AAMs with varying ratios of industrial wastes.

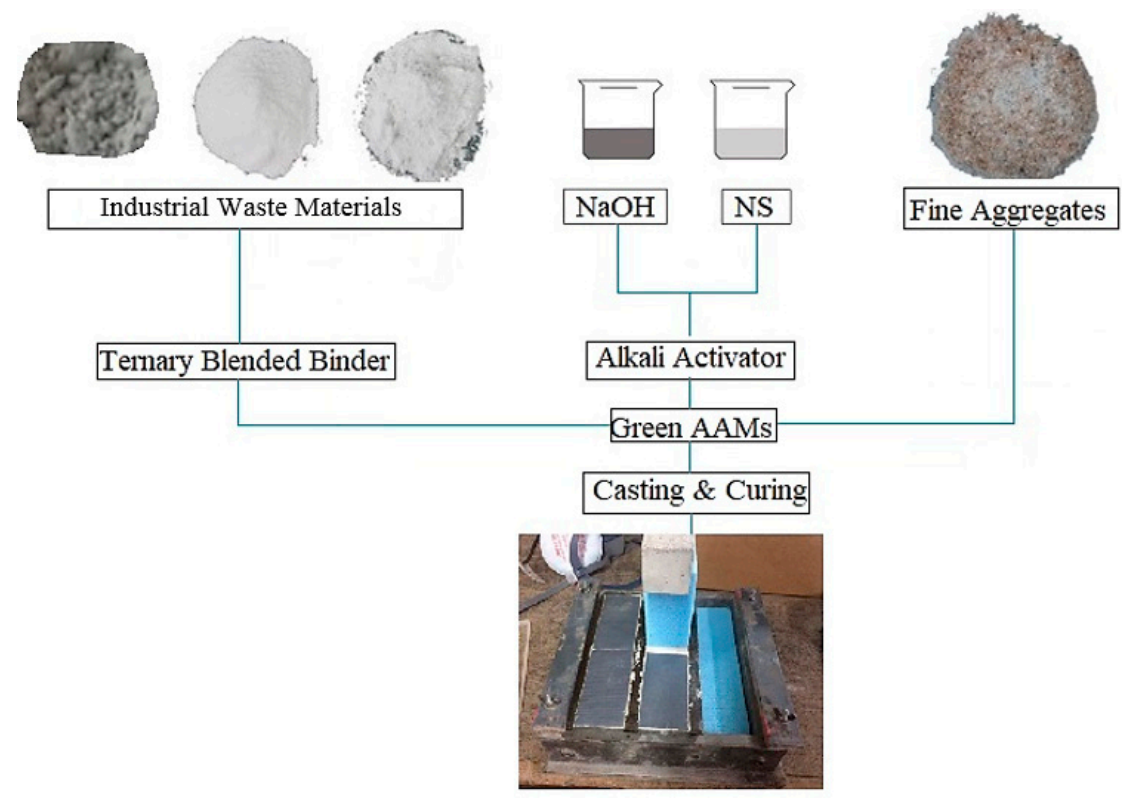

Figure 1. Procedure of producing green alkali-activated mixes (AAMs) mortars.

A standard test rig was used for the experimental derivation of compressive strength (CS), tensile strength (TS), and flexural strength (FS). All the mechanical properties were recorded at the age of 1, 3, 7, 28 days, following ASTM C109-109M [24]. Cube molds of the dimension $(50 \times 50 \times 50) \mathrm{mm}$ were prepared for hardened tests of compressive strength. Prisms of the dimension $(40 \times 40 \times 160) \mathrm{mm}$ were used to prepare the samples for flexural strength test, while for tensile strength tests, cylinders were prepared with a diameter of $75 \mathrm{~mm}$ and depth of $150 \mathrm{~mm}$. For the compressive test, a universal testing machine was used, and a constant loading rate of $2.5 \mathrm{kN} / \mathrm{s}$ was applied to all tested specimens. The equivalent compressive strength values were hence recorded automatically, on the basis of the specimens' size. A similar approach was applied to calculate the TS of 
specimens in compliance with ASTM C496/C496M [25], in which the splitting TS can be predicted as:

$$
\mathrm{TS}=2 P / \pi D L
$$

In Equation (1), TS is the splitting tensile capacity (MPa), $P$ is the maximum axial load resistance $(\mathrm{N}), D$ is the diameter of the cylinder $(\mathrm{mm})$, and $L$ is the length of the cylinder (mm).

The flexural strength-also called modulus of rupture, bend strength, or fracture strength-is another essential measure of the mechanical performance for brittle materials. This is defined as the material's ability to resist deformation under load. The flexural strength test was carried out using the ASTM C78/C78M [26] procedure, where adequately cured prismatic specimens were tested. Similar to CS and TS, the universal testing machine was employed, in which the FS value is expressed as:

$$
\mathrm{FS}=3 F L / 2 b d^{2}
$$

where $F$ is the applied load at the fracture point $(\mathrm{N}), L$ is length of the support span (mm), $b$ is the width (mm), and $d$ is the thickness ( $\mathrm{mm})$.

All the CS, TS, and FS tests were performed on three specimens for each design mix, after each curing age, and their average prediction was considered. Several test methods such as X-ray diffraction (XRD) and scanning electron microscopy (SEM) were also adopted to access the microstructural properties of alkali-activated binder incorporating industrial wastes. The XRD test is a rapid and straightforward technique for the non-destructive characterization of crystalline materials. It provides information on phases, preferred crystal orientations, and structural parameters. In this research study, the alkali-activated paste powders were scanned in the 2-theta range of 5 to 60 degrees at the step size of 0.02 degrees. To analyze XRD data, the MDI Jade software (version 6.5) and Match software (version 3.10.2.173) were used to verify the glassy nature of the specimens. SEM with high magnifications was finally used to examine the surface morphology of the tested specimens. Operating conditions consisted in a beam energy of $20 \mathrm{keV}$, beam current of $726 \mathrm{pA}$, and count time of $10 \mathrm{~s}$ with 3500 counts per second, reported as relative atomic concentrations.

At the first stage, the alkali-activated samples were collected from the specimens subjected to the CS test setup, and then each sample was sowed on to the double cellophane sheets followed by attaching to the coin. In the second stage, each sample was placed in the brass stub holder and dried for 5 minutes using IR radiations before using a Blazer sputter coater to cover with gold. The SEM was in fact performed by coating the mortar samples with a thin layer of gold ( $1.5 \mathrm{~nm}$ to $3.0 \mathrm{~nm}$ its thickness) prior to the analysis. The resultant patterns were thus monitored using $20 \mathrm{kV}$ with $1000 \times$ magnification, at a working distance in the range of 1 to $50 \mathrm{~mm}$, depending on the operational conditions. Significant morphology images were captured immediately after, by selecting reasonably high image magnifications.

\section{Test Results}

\subsection{Mechanical Properties}

Table 3 shows the binder constitution and 28-day CS, FS, and TS for all 42 studied AAMs. Table 3 shows that the highest mechanical properties were achieved by AAMs with a high volume of GBFS, while the AAMs with a high volume of POFA resulted in the lowest mechanical properties. The mechanical properties in AAMs with a high volume of WCP also were not satisfactory.

However, increasing the GBFS percentage in the binder mass improved mechanical behaviour in this category. The mechanical features in AAMs with a high-volume FA were significantly dependent on the percentage of GBFS in the binder mass, where substituting the GBFS by POFA significantly decreased the CS. Overall, the average CS of studied 
AAMs was $61.3 \mathrm{MPa}$, which is very satisfactory with much lower embodied energy and $\mathrm{CO}_{2}$ emission compared to traditional cement-based mortar.

Table 3. Binder constitutions of AAMs, with the corresponding mechanical properties.

\begin{tabular}{|c|c|c|c|c|c|c|c|}
\hline \multirow{2}{*}{$\begin{array}{c}\text { AAM } \\
\text { Design }\end{array}$} & \multicolumn{4}{|c|}{ Binder (\% Mass) } & \multicolumn{3}{|c|}{ Mechanical Properties } \\
\hline & FA & GBFS & WCP & POFA & $\begin{array}{c}\text { 28-Day CS } \\
\text { (MPa) }\end{array}$ & $\begin{array}{c}\text { 28-Day TS } \\
\text { (MPa) }\end{array}$ & $\begin{array}{c}\text { 28-Day FS } \\
\text { (MPa) }\end{array}$ \\
\hline \multicolumn{8}{|c|}{ High Volume FA } \\
\hline 1 & 0.700 & 0.300 & 0.000 & 0.000 & 78.180 & 4.560 & 8.270 \\
\hline 2 & 0.700 & 0.200 & 0.000 & 0.100 & 65.890 & 4.340 & 7.150 \\
\hline 3 & 0.600 & 0.400 & 0.000 & 0.000 & 80.510 & 5.180 & 10.780 \\
\hline 4 & 0.600 & 0.300 & 0.000 & 0.100 & 81.700 & 4.770 & 10.680 \\
\hline 5 & 0.600 & 0.200 & 0.000 & 0.200 & 52.600 & 3.080 & 6.000 \\
\hline 6 & 0.500 & 0.500 & 0.000 & 0.000 & 80.460 & 5.060 & 10.740 \\
\hline 7 & 0.500 & 0.400 & 0.000 & 0.100 & 76.900 & 4.860 & 9.490 \\
\hline 8 & 0.500 & 0.300 & 0.000 & 0.200 & 70.400 & 4.640 & 8.120 \\
\hline 9 & 0.500 & 0.200 & 0.000 & 0.300 & 46.240 & 3.460 & 6.430 \\
\hline \multicolumn{8}{|c|}{ High Volume POFA } \\
\hline 10 & 0.000 & 0.300 & 0.000 & 0.700 & 34.530 & 2.240 & 4.140 \\
\hline 11 & 0.100 & 0.200 & 0.000 & 0.700 & 23.040 & 1.370 & 2.760 \\
\hline 12 & 0.000 & 0.400 & 0.000 & 0.600 & 45.960 & 3.310 & 5.880 \\
\hline 13 & 0.100 & 0.300 & 0.000 & 0.600 & 37.800 & 2.620 & 4.590 \\
\hline 14 & 0.200 & 0.200 & 0.000 & 0.600 & 28.800 & 2.180 & 3.580 \\
\hline 15 & 0.000 & 0.500 & 0.000 & 0.500 & 55.640 & 4.760 & 7.570 \\
\hline 16 & 0.100 & 0.400 & 0.000 & 0.500 & 47.100 & 3.660 & 6.010 \\
\hline 17 & 0.200 & 0.300 & 0.000 & 0.500 & 40.600 & 2.980 & 4.880 \\
\hline 18 & 0.300 & 0.200 & 0.000 & 0.500 & 36.800 & 2.570 & 4.370 \\
\hline \multicolumn{8}{|c|}{ High Volume GBFS } \\
\hline 19 & 0.300 & 0.700 & 0.000 & 0.000 & 85.090 & 5.800 & 10.860 \\
\hline 20 & 0.200 & 0.700 & 0.000 & 0.100 & 97.750 & 7.160 & 12.180 \\
\hline 21 & 0.100 & 0.700 & 0.000 & 0.200 & 86.400 & 5.670 & 10.770 \\
\hline 22 & 0.000 & 0.700 & 0.000 & 0.300 & 70.530 & 5.440 & 10.260 \\
\hline 23 & 0.400 & 0.600 & 0.000 & 0.000 & 80.680 & 5.560 & 10.710 \\
\hline 24 & 0.300 & 0.600 & 0.000 & 0.100 & 72.440 & 5.140 & 9.540 \\
\hline 25 & 0.200 & 0.600 & 0.000 & 0.200 & 71.930 & 5.040 & 9.560 \\
\hline 26 & 0.100 & 0.600 & 0.000 & 0.300 & 70.840 & 4.890 & 9.360 \\
\hline 27 & 0.000 & 0.600 & 0.000 & 0.400 & 70.220 & 4.770 & 9.140 \\
\hline 28 & 0.500 & 0.500 & 0.000 & 0.000 & 80.460 & 5.060 & 10.740 \\
\hline 29 & 0.400 & 0.500 & 0.000 & 0.100 & 80.430 & 5.110 & 10.540 \\
\hline 30 & 0.300 & 0.500 & 0.000 & 0.200 & 67.220 & 4.810 & 8.530 \\
\hline 31 & 0.200 & 0.500 & 0.000 & 0.300 & 65.140 & 4.420 & 7.980 \\
\hline 32 & 0.100 & 0.500 & 0.000 & 0.400 & 56.340 & 4.360 & 7.540 \\
\hline 33 & 0.000 & 0.500 & 0.000 & 0.500 & 55.640 & 4.280 & 7.570 \\
\hline
\end{tabular}


Table 3. Cont.

\begin{tabular}{cccccccc}
\hline \multicolumn{7}{c}{ High Volume WCP } \\
\hline 34 & 0.000 & 0.300 & 0.700 & 0.000 & 34.020 & 2.680 & 4.620 \\
\hline 35 & 0.100 & 0.200 & 0.700 & 0.000 & 22.400 & 1.750 & 2.970 \\
\hline 36 & 0.000 & 0.400 & 0.600 & 0.000 & 68.440 & 5.670 & 9.260 \\
\hline 37 & 0.100 & 0.300 & 0.600 & 0.000 & 52.080 & 5.160 & 7.670 \\
\hline 38 & 0.200 & 0.200 & 0.600 & 0.000 & 46.760 & 3.940 & 6.580 \\
\hline 39 & 0.000 & 0.500 & 0.500 & 0.000 & 74.120 & 5.300 & 10.120 \\
\hline 40 & 0.100 & 0.400 & 0.500 & 0.000 & 66.190 & 4.990 & 9.070 \\
\hline 41 & 0.200 & 0.300 & 0.500 & 0.000 & 60.170 & 4.710 & 8.220 \\
\hline 42 & 0.300 & 0.200 & 0.500 & 0.000 & 56.470 & 4.510 & 7.710 \\
\hline Average & & & & & 61.3 & 4.33 & 7.927 \\
\hline ST.DEV. & & & & & 18.70 & 1.23 & 2.47 \\
\hline
\end{tabular}

\subsection{Structural Morphology}

The microstructure and composition of industrial waste hydration products are crucial for defining the properties of hardened mortar. The main hydration products are calcium silicate hydrate gels (C-S-H) and calcium hydroxide $(\mathrm{CH})$, aluminate/aluminoferrite phases (AFt and AFm type phases) [27]. Among these hydration products, the most important one is C-S-H gel because it is the principal binding phase in cement-based systems, and it is responsible for strength, density, and so forth. By using morphology tests, microstructure and chemical composition define the final properties of the hardened mortar.

\subsubsection{Scanning Electron Microscopy (SEM)}

The high-resolution, SEM images are useful within materials science to test the quality of materials, ensuring that they are an appropriate option for the required purpose and can be used to predict and prevent material failure.

The SEM images showing the microstructure of AAMs with a high volume of FA contents are shown in Figure $2 \mathrm{a}$, b and c with 50\%, 60\%, and 70\% FA, respectively. Figure $2 \mathrm{a}$ reveals that the microstructure of the sample containing a high amount of FA was less dense compared to other matrices, due to a lack of C-S-H gel formation. Once the content of FA was decreased and replaced by GBFS, the microstructure of AAMs was enhanced and provided a denser surface, as shown in Figure $2 b$ and c. The SEM images also acknowledged that in AAMs with 70\% FA, the gel structure and unreacted/partially reacted particles were extensively distributed over the surface, whereas by decreasing the FA content to $60 \%$ and $50 \%$, a dense gel dominated the surface of AAMs.

Figure 3 shows the effects of POFA replacement by GBFS on AAMs with 60\% FA. The SEM image clearly indicates that the design mixes with zero POFA (60\% FA and $40 \%$ GBFS) have a dense structure (Figure 3a). On the other hand, once the POFA percentage, replaced by GBFS, was increased from $0 \%$ to $20 \%$, the dense gel phase was decreased, and the AAMs enclosed unreacted/partially reacted phase (Figure 3b). Increasing the content of POFA affected the calcium content and hence reduced the C-S-H product formation with poor microstructure. This particular issue also negatively affects the mechanical properties, where the CS decreased from 80.5 to $52.6 \mathrm{MPa}$ by replacing POFA with GBFS from $0 \%$ to $20 \%$, as shown in Table 3. 

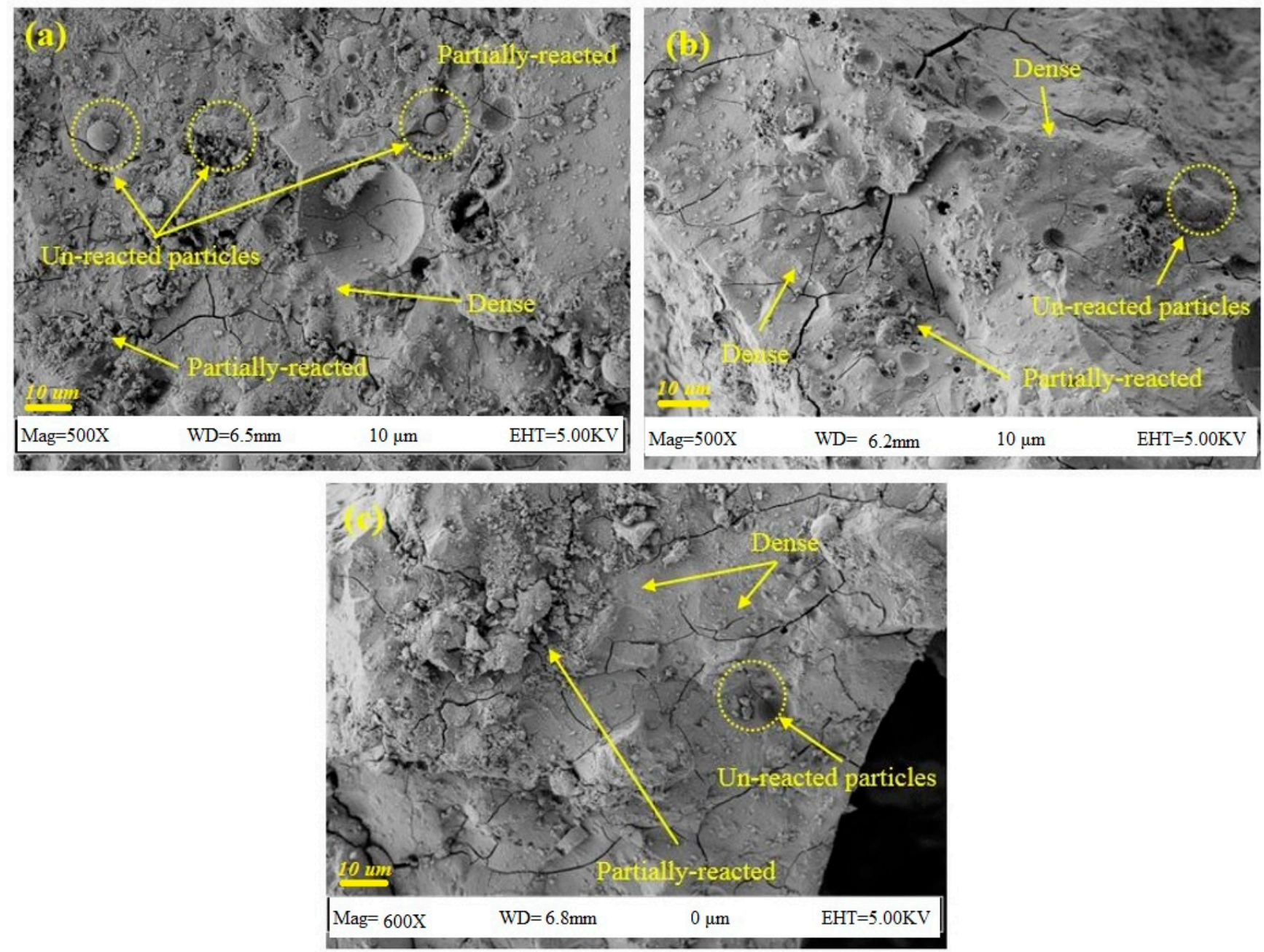

Figure 2. Scanning electron microscopy (SEM) images of AAMs containing a high volume of fly ash (FA), with evidence of (a) $70 \%$ FA, (b) $60 \%$ FA, (c) $50 \%$ FA.
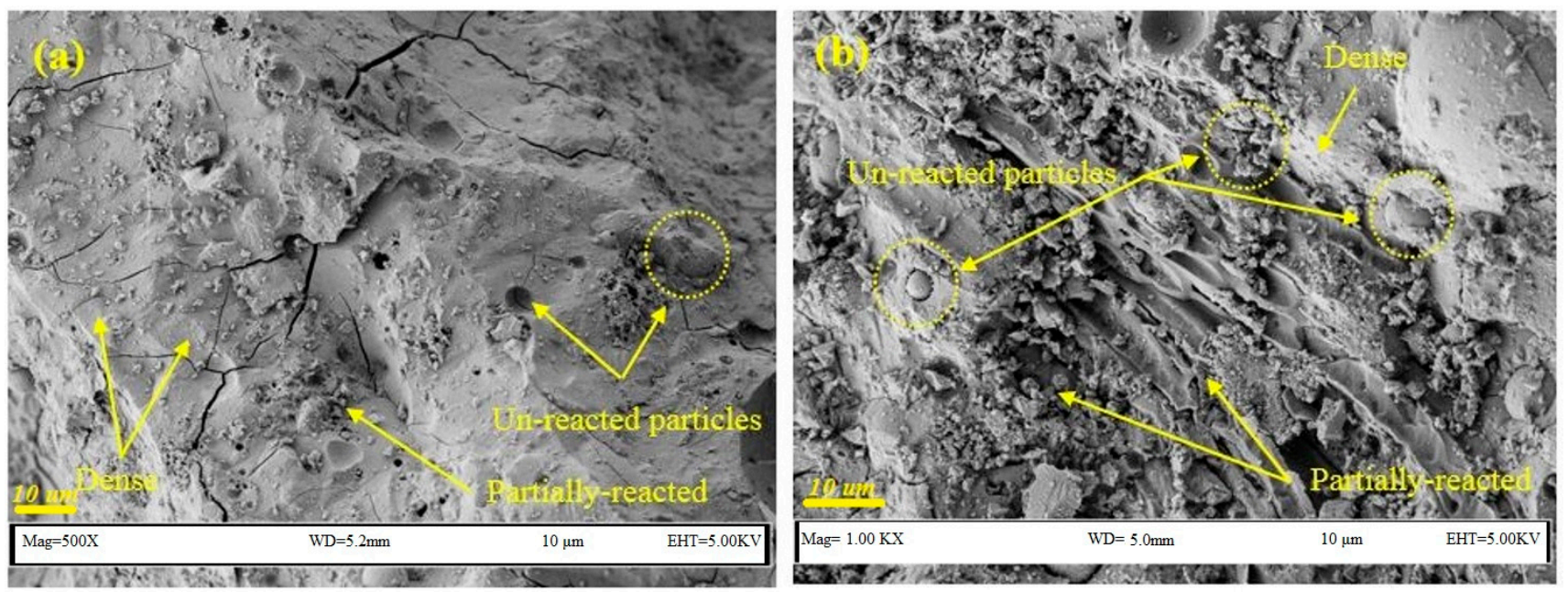

Figure 3. SEM images of palm oil fly ash (POFA) replacement by granulated blast-furnace slag (GBFS) in AAMs with $60 \%$ FA, with evidence of (a) 0\% POFA, (b) 20\% POFA.

Figure 4 shows SEM images of AAMs with a high volume of WCP. The result indicates the creation of a larger amount of crystalline $\mathrm{Ca}(\mathrm{OH})_{2}$ in hexagonal plate-like structures (unreacted particles/partially reacted matrix) in AAMs with $60 \%$ and $70 \%$ of 
WCP (Figure 4a,b). This issue can be explained by the hydration process of an excess amount of $\mathrm{CaO}$ in the GBFS and FA that produced an elevated amount of $\mathrm{Ca}(\mathrm{OH})_{2}$ crystals. When GBFS was mixed with FA, it shaped a hydrated binding cement paste (HCP) of calcium silicate hydrate (C-S-H). The formation of a massive amount of C-S-H crystals in AAMs with $50 \%$ of WCP made it denser, and this was attributed to the pozzolanic reaction of $\mathrm{SiO}_{2}$ with $\mathrm{Ca}(\mathrm{OH})_{2}$ during the hydration process (Figure 4c). Subsequently, such dense microstructures contributed to enhancing the CS of mix designs.
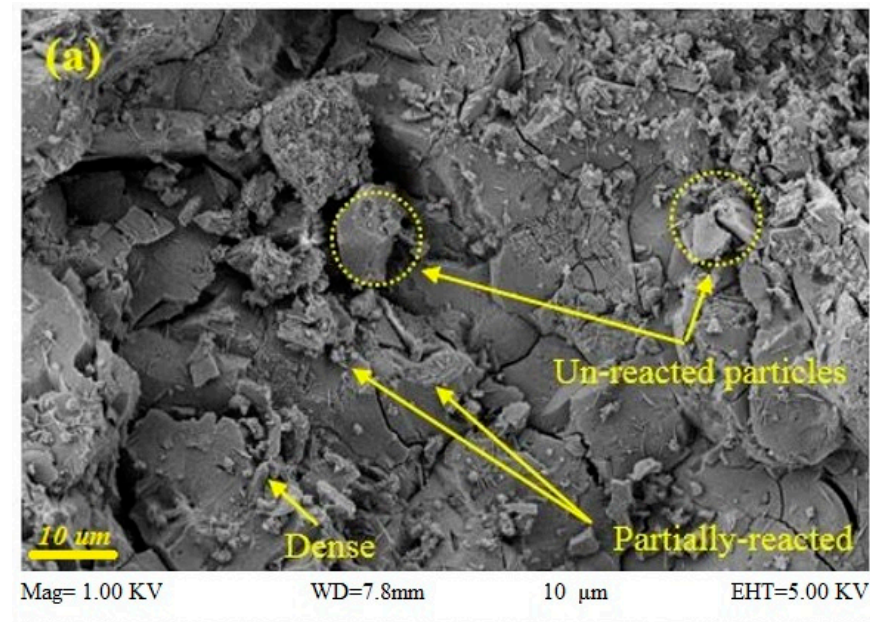

$$
10 \mu \mathrm{m}
$$

$$
\mathrm{EHT}=5.00 \mathrm{KV} \mathrm{Mag}=1.00 \mathrm{KV}
$$
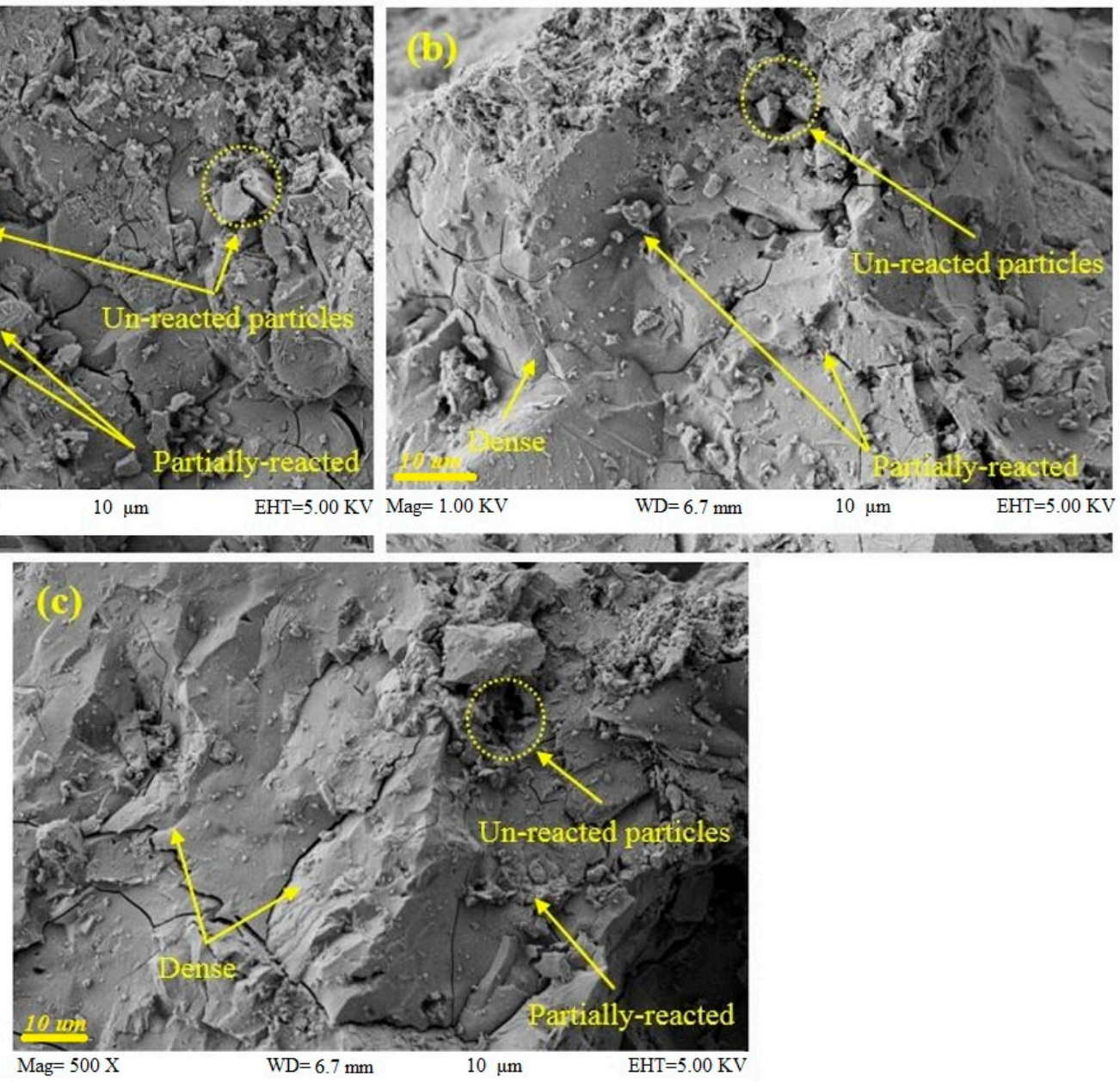

Figure 4. SEM images of AAM designs with a high volume of waste ceramic powder (WCP), with evidence of (a) $70 \%$ WCP, (b) $60 \% \mathrm{WCP}$, and (c) $50 \% \mathrm{WCP}$.

\subsubsection{X-ray Diffraction (XRD)}

To identify the crystal phase of geopolymerization products and evaluate the effects of silicate, $\mathrm{Al}$, and $\mathrm{Ca}$ on the derived C-S-H gel, with different substitution ratios of industrial wastes in the AAMs at the age of 28 days, XRD patterns were recorded between 0 and 60 degrees.

Figure 5 shows the XRD patterns of AAMs containing a high volume of FA, where the peak intensity corresponds to crystalline quartz $\left(\mathrm{SiO}_{2}\right)$ and mullite $\left(3 \mathrm{Al}_{2} \mathrm{O}_{3} 2 \mathrm{SiO}_{2}\right.$ or $2 \mathrm{Al}_{2} \mathrm{O}_{3}$ $\mathrm{SiO}_{2}$ ) phases in AAMs with $60 \%$ and $70 \%$ FA. The crystalline phases' peak intensity was increased with an increasing amount of FA from $50 \%$ to $60 \%$ to $70 \%$, and the C-S-H gel peak was replaced by the quartz peak $\left(\mathrm{SiO}_{2}\right)$, where more quartz appeared to be non-reactive with $70 \%$ of FA content. The products formed due to the reaction between the glassy fraction of FA and GBFS that consisted of very poor crystalline phases. Kumar et al. [28] have reported that the FA consists of reactive and refractory glass, where the reactive glass only participates in the geopolymerization. The broad and diffused background peak with 
a maxima of around 10 degrees emerged from the short-range order of the hydrotalcite $\left(\mathrm{Mg}_{6} \mathrm{Al}_{2} \mathrm{CO}_{3} \mathrm{OH}_{16} 4 \mathrm{H}_{2} \mathrm{O}\right)$ in all AAMs with different content of FA. The peaks around 24 and 33.8 degrees were also allocated to nepheline $\left(\mathrm{Na}_{3} \mathrm{KAl}_{4} \mathrm{Si}_{4} \mathrm{O} 16\right)$.

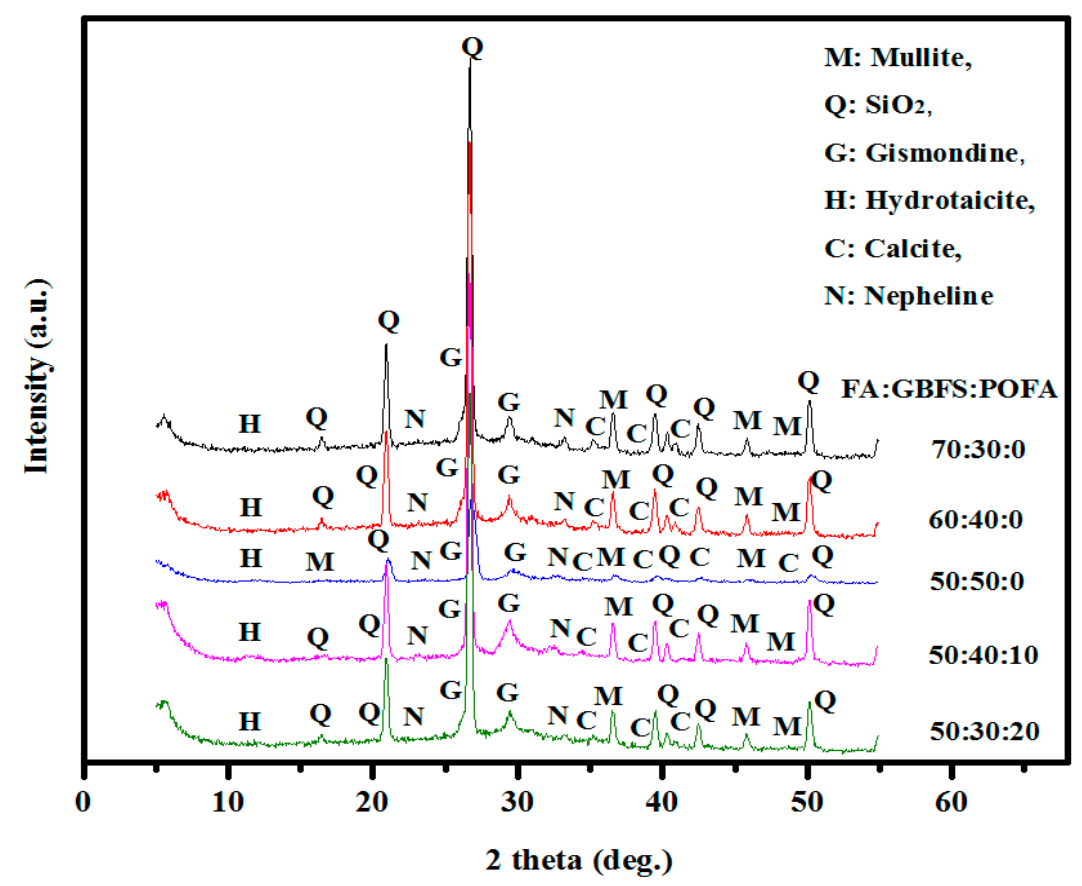

Figure 5. X-ray diffraction (XRD) pattern of AAMs containing a high volume of FA and POFA replaced by GBFS containing 50\% FA.

Figure 5 also shows the XRD patterns of AAMs with 50\% FA and a different GBFS replacement ratio by POFA. Figure 5 indicates that peak intensity corresponds to the quartz $\left(\mathrm{SiO}_{2}\right)$ as the POFA replacement was increased in AAMs (with maxima around 28 degrees) while the peak intensity is dedicated to C-S-H in the design mix with $0 \%$ POFA. Furthermore, the C-S-H gel peak intensity at 31 degrees was enhanced when the POFA content was increased to $10 \%$ and $20 \%$, improving the CS of AAMs. There is a reduction in the C-S-H gel peak intensity in a design mix with a 30\% POFA. In this particular design mix, the quartz peak at 28 degrees showed low intensity with higher width. The low product of C-S-H gel reduced the CS from 70.4 to $46.2 \mathrm{MPa}$ as the POFA replaced by GBFS increased from $20 \%$ to $30 \%$, as shown in Table 3 .

\subsubsection{Fourier-Transform Infrared Spectroscopy (FTIR)}

In various AAMs matrices, the formation of reaction products and geopolymerization degree were identified using FTIR measurements. The FTIR test is a chemical analysis method that searches for $\mathrm{Si}-\mathrm{O}$ and $\mathrm{Al}-\mathrm{O}$ reaction zones in AAMs. In such a matrix, the development of C-S-H gel occurred with the dissolution of minerals, due to the alkaline activators' addition to the base materials. This resulted in the release of $\mathrm{Al}$ via the hydroxylation, which in turn caused the attachment of $\mathrm{OH}^{-}$ions present in the alkali to form the $\mathrm{Al}-\mathrm{O}-\mathrm{Al}$ bond by rupturing the weak bonds. Then, a negatively charged $\mathrm{Al}$ in IV fold coordination was liberated. Finally, a charge balance was achieved by $\mathrm{Ca}$, which reacted preferentially over $\mathrm{Na}$ [29].

GBFS contains higher $\mathrm{CaO}$ than FA and POFA, leading to a high potential for $\mathrm{Ca}$ solubility in the mixture. The quantity of soluble Ca depends on the volume of GBFS present in the mixture, which directly affects the C-S-H gel. The unit oligomer of ( $\mathrm{Si}-\mathrm{O}-\mathrm{Al})$ Ca could be built up in chains, sheets, or a three-dimensional framework through the polycondensation process to result in the product hardening [30]. Furthermore, Davidovits described the Ca-based AAMs as the condensation resulting from the hydroxylation of 
the gehlenite and akermanite phase to form cyclo Ca-ortho-sialate-disiloxo $\left(\mathrm{C}_{3} \mathrm{AS}_{3}\right)$ and Ca-disiloxonate hydrate C-S-H, respectively. Figure 6 shows the FTIR spectra and FTIR fingerprint zone of AAMs with a high volume of FA.

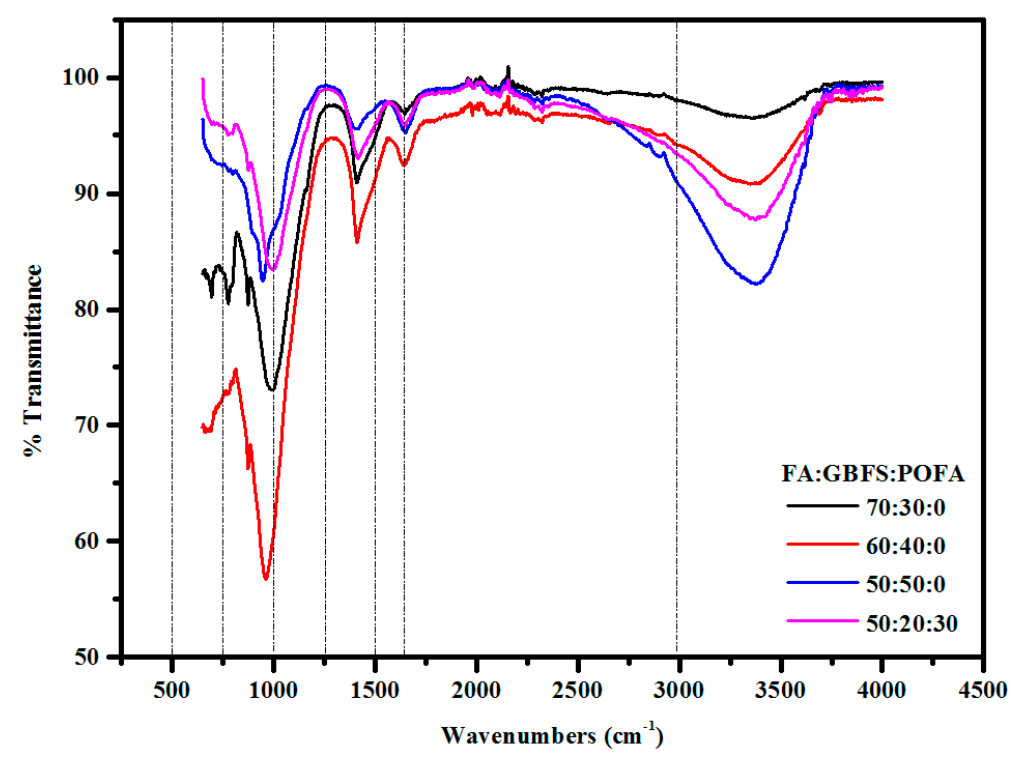

(a)

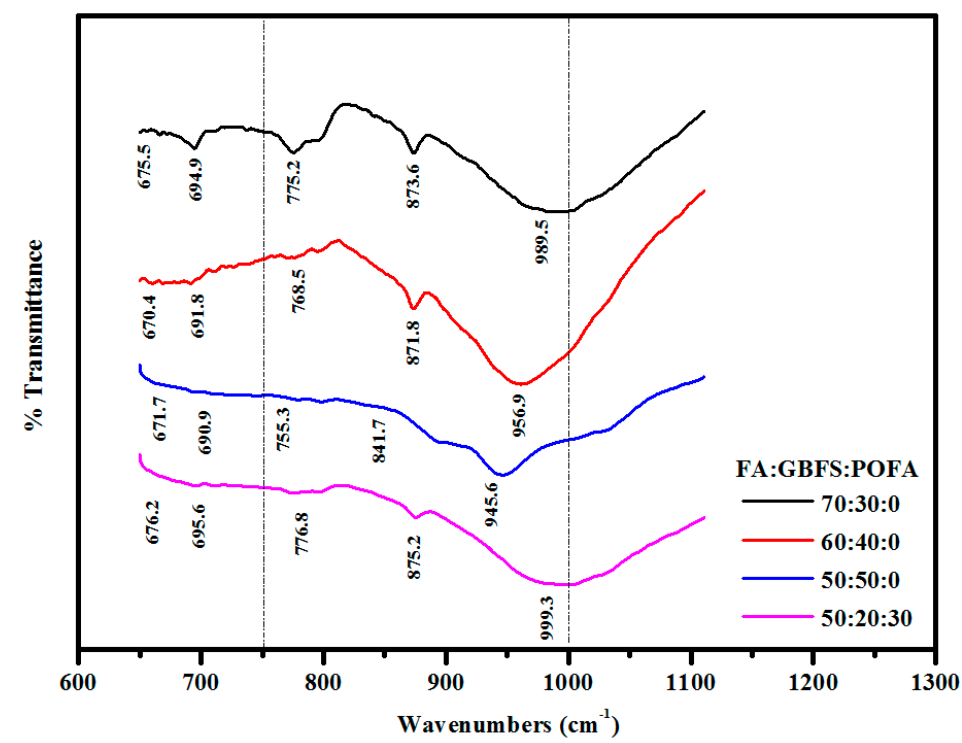

(b)

Figure 6. (a) Fourier-transform infrared spectroscopy (FTIR) spectra and (b) FTIR fingerprint zone of AAMs with a high volume of FA.

Following the information provided in Figure 6, Table 4 demonstrates the FTIR peak positions and band assignments.

Table 4. Fourier-transform infrared spectroscopy (FTIR) peak positions and band assignments.

\begin{tabular}{|c|c|c|c|c|c|c|c|c|}
\hline \multirow{2}{*}{$\begin{array}{c}\text { AAM } \\
\text { FA:GBFS:POFA }\end{array}$} & \multicolumn{2}{|c|}{ Ratio } & \multirow{2}{*}{$f_{c}(\mathrm{MPa})$} & \multicolumn{5}{|c|}{ Band Position $\left(\mathrm{cm}^{-1}\right)$ and Assignments } \\
\hline & Si/Al & $\mathrm{Ca} / \mathrm{Si}$ & & Al-O & Si-O & $\mathrm{AlO}_{4}$ & $\mathrm{CSH}$ & $\mathrm{C}(\mathrm{N}) \mathrm{ASH}$ \\
\hline 70:30:0 & 2.10 & 0.39 & 78.2 & 675.5 & 694.9 & 775.2 & 873.6 & 989.5 \\
\hline 60:40:0 & 2.38 & 0.39 & 80.5 & 670.4 & 691.8 & 768.5 & 871.8 & 956.9 \\
\hline 50:50:0 & 2.22 & 0.65 & 80.6 & 671.7 & 690.9 & 755.3 & 871.4 & 945.6 \\
\hline $50: 20: 30$ & 3.02 & 0.29 & 46.2 & 676.2 & 695.6 & 776.8 & 875.2 & 999.3 \\
\hline
\end{tabular}


The critical outcomes from Table 4 can be discussed as follows:

- By increasing the FA content from $50 \%$ to $70 \%$, the band of the C(N)ASH gel product increases from 945.6 to $989.5 \mathrm{~cm}^{-1}$.

- By increasing the FA content from 50\% to 70\%, the C-S-H and Si-O band frequency increases, leading to a less homogenous structure of AAMs for $60 \%$ and $70 \%$ FA content, and subsequently smaller silicate re-organization compares to the $50 \% \mathrm{FA}$ mix design.

- The band of $945.6 \mathrm{~cm}^{-1}$ presented in the AAMs containing 50\% FA, 50\% GBFS, and $0 \%$ POFA achieves the highest CS of $80.6 \mathrm{MPa}$.

- The broad band at $1647 \mathrm{~cm}^{-1}$ and a weak peak at $3353 \mathrm{~cm}^{-1}$ are allocated to the stretching vibrations of $\mathrm{O}-\mathrm{H}$ bonds and $\mathrm{H}-\mathrm{O}-\mathrm{H}$ bending vibrations of interlayer adsorbed $\mathrm{H}_{2} \mathrm{O}$ molecules, respectively [31]. On the basis of these values, increasing the FA content is found to cause structural changes in the examined mixes, which can be attributed to the reduction of C-S-H formation with $\mathrm{C}(\mathrm{N})-\mathrm{A}-\mathrm{S}-\mathrm{H}$ type gels and to the increase of the amount of $\mathrm{Si}$ and $\mathrm{Al}$. These changes slow down the rate of geopolymerization and negatively affect the mechanical strength of AAMs.

- $\quad$ GBFS released soluble Ca that displaced the Si atoms from Si-O bonds, leading to a reduction in the vibrational frequency. Therefore, it can be concluded that the frequency of vibration decreases with the increase in the molecular molar mass of the attached atoms.

- The addition of FA or POFA caused the increment in the $\mathrm{SiO}_{2} / \mathrm{Al}_{2} \mathrm{O}_{3}$ ratio and the vibrational frequency of Si-O-Si (Al).

- The band corresponding to $\mathrm{AlO}_{4}$ shifted from $755.3 \mathrm{~cm}^{-1}$ to 768.5 to $775.2 \mathrm{~cm}^{-1}$ in samples prepared with $50 \%, 60 \%$, and $70 \%$ FA binder, respectively.

\section{Prediction of Mechanical Properties Using ANN}

\subsection{Methods}

\subsubsection{Feed-Forward ANN and Krill Herd Algorithm}

The multilayer feed-forward network provides a reliable feature for the ANN structure and, therefore, was used in this research. The multilayer feed-forward network comprises three individual layers: the input layer, where the data are defined to the model; the hidden layer/s, where the input data are processed; and finally, the output layer, where the results of the feed-forward ANN are produced. Each layer contains a group of nodes referred to as neurons that are connected to the proceeding layer. The neurons in hidden and output layers consist of three components; weights, biases, and an activation function that can be continuous, linear, or nonlinear. Standard activation functions include nonlinear sigmoid functions (logsig, tansig) and linear functions (poslin, purelin) [32]. Once the architecture of a feed-forward ANN (number of layers, number of neurons in each layer, activation function for each layer) is selected, the weight and bias levels should be adjusted using training algorithms. One of the most reliable ANN training algorithms is the backpropagation (BP) algorithm, which distributes the network error to arrive at the best fit or minimum error $[33,34]$.

The Krill Herd algorithm is a smart group algorithm for optimization in engineering disciplines [35]. This algorithm has been used to achieve more efficiency in civil engineering. It refers to a novel metaheuristic algorithm to determine the weight optimization of each ANN model. In this algorithm, krill individuals search for food in different places and are presented as different decision variables. The objective is to calculate the distance between krill individuals and the availability of extra food, related to the cost. Therefore, the time-dependent position of a krill individual is measured by functional processes, which include the process of foraging, search displacement, and random physical diffusion [36]. In the process of foraging motion, the individual krill velocity is always affected by another krill displacement in the multidimensional search space, where the velocity changes dramatically and dynamically on the basis of the internal influence parameters, including the influence of the target group and the repulsive effect. 
Equations (3) to (8) can efficiently formulate the displacement description of a krill individual [36]:

$$
\begin{gathered}
\theta_{i}^{\text {new }}=\epsilon_{i} \theta_{i}^{\text {max }}+\mu_{n} \theta_{i}^{\text {old }} \\
\epsilon_{i}=\epsilon_{i}^{\text {local }}+\epsilon_{i}^{\text {target }} \\
\epsilon_{i}^{\text {local }}=\sum_{i=0}^{N s-1} f_{i j} x_{i j} \\
f_{i j}=\frac{f_{i}-f_{j}}{f_{w}-f_{b}} \\
x_{i j}=\frac{x_{i}-x_{j}}{\left|f_{w}-f_{b}\right| \text { rand }(0.1)} \\
\epsilon_{i}^{\text {target }}=2\left(\operatorname{rand}(0.1)+\frac{i}{i_{\text {max }}}\right) f_{i}^{\text {best }} x_{i}^{\text {best }}
\end{gathered}
$$

where $\theta_{i}^{\max }$ represents the highest motion created and $\theta_{i}^{\text {old }}$ is the motion created; $\mu_{n}$ represents the algebraic magnitude of the motion created, while the target effects are represented by $\epsilon_{i}^{\text {local }}$ and $\epsilon_{i}^{\text {target }}$.

Moreover, $f_{w}$ and $f_{b}$ are the worst and the best population positions, respectively; $f_{i}$ and $f_{j}$ are the $i^{\text {th }}$ and $j^{\text {th }}$ krill individual proportions. The current number and the highest number are provided by $i_{\max }$. To identify the neighboring members of each krill individual, a sensor distance parameter $\left(S D_{i}\right)$ is used [36]:

$$
S D_{i}=\frac{1}{5 n_{p}} \sum_{i=0}^{n_{p}-1}\left|x_{i}-x_{j}\right|
$$

where $n_{p}$ represents the number of krill individuals in the population, while $x_{i}$ and $x_{j}$ are the positions of $i^{\text {th }}$ and $j^{\text {th }}$ krill, respectively [36].

\subsubsection{Input and Output Parameters}

Considering the information about the contents of constituents in each AAM, as provided in Table 2, and their mechanical properties at the age of 1, 3, 7, 28 days (as summarized in Table 3), Table 5 defines the input and output parameters along with their statistical properties that were used for training the ANN model.

Table 5. Statistical parameters of input and output parameters.

\begin{tabular}{cccccc}
\hline Statistical Index & Average & ST.DEV. & Max & Min & Type \\
\hline FA & 0.25 & 0.21 & 0.7 & 0 & Input \\
GBFS & 0.41 & 0.16 & 0.7 & 0.2 & Input \\
WCP & 0.12 & 0.24 & 0.7 & 0 & Input \\
POFA & 0.22 & 0.23 & 0.7 & 0 & Input \\
Si:Al (ratio) & 4.03 & 1.58 & 8.63 & 2.1 & Input \\
Ca:Si (ratio) & 0.52 & 0.23 & 0.97 & 0.17 & Input \\
Ca:Al (ratio) & 2.05 & 1.09 & 4.41 & 0.66 & Input \\
Age (day) & 9.75 & 10.79 & 28 & 1 & Input \\
Compressive Strength (MPa) & 40.61 & 20.55 & 97.75 & 7.61 & Output \\
Tensile Strength (MPa) & 2.94 & 1.52 & 7.16 & 0.34 & Output \\
Flexural Strength (MPa) & 5.1 & 2.77 & 12.18 & 0.64 & Output \\
\hline
\end{tabular}

Since the behaviour and number of input data should be statistically evaluated against the output data, Figure 7 also shows the histograms of output data (CS, TS, and FS mechanical properties). 


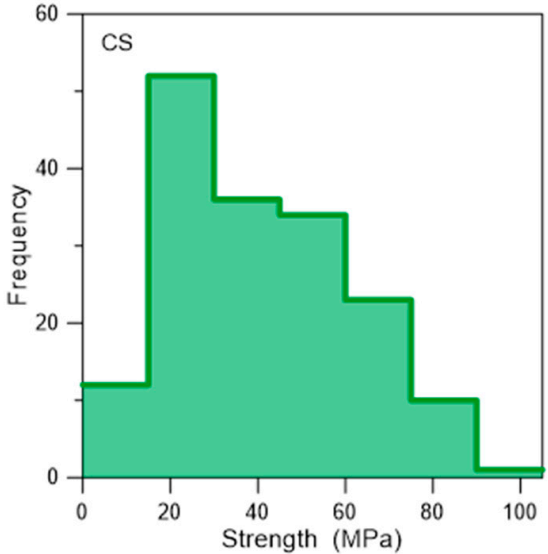

(a)

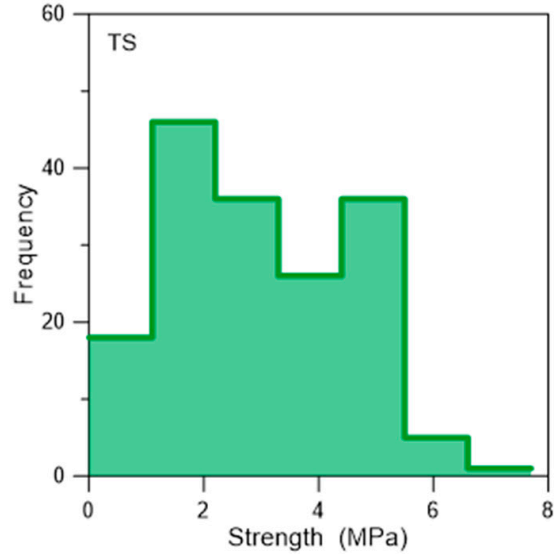

(b)

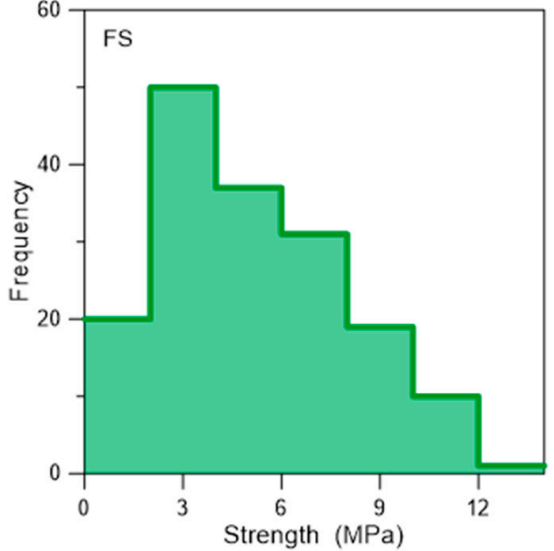

(c)

Figure 7. Histogram of output data for (a) compressive strength (CS), (b) tensile strength (TS), and (c) flexural strength (FS) parameters.

\subsubsection{Developing the Topology and Structure of Feed-Forward ANN}

The ANN used in this study is a new feed-forward model. Up to $70 \%$ of input data (out of 168 samples) was used for training, and the remaining 30\% part was considered for testing the network. According to the characteristics of the available input data and the number of outputs, a two-layer ANN was proposed in the initial attempt, and its adequacy was evaluated by using several measures. Table 6 shows the structure and topology of this feed-forward ANN.

Table 6. Structure and topology of the proposed feed-forward artificial neural network (ANN).

\begin{tabular}{ccccccc}
\hline & \multicolumn{5}{c}{ Features of ANN } \\
\hline $\begin{array}{c}\text { Number of } \\
\text { Input }\end{array}$ & $\begin{array}{c}\text { Number of } \\
\text { Output }\end{array}$ & $\begin{array}{c}\text { Neural } \\
\text { Network }\end{array}$ & Hidden Layer & Node & Learning Role & $\begin{array}{c}\text { Transfer } \\
\text { Function }\end{array}$ \\
\hline 8 & 3 & newff & 2 & $9-8$ & Levenberg-Marquardt & tansig \\
\hline
\end{tabular}

To optimize the weights of the proposed ANN model, the Krill Herd algorithm was used as a new metaheuristic algorithm in building materials technology. Table 7 shows the features of KHA, once applied in the proposed feed-forward ANN.

Table 7. Properties of the Krill Herd algorithm.

\begin{tabular}{ccccc}
\hline \multicolumn{4}{c}{ Features of Krill Herd Algorithm } \\
\hline $\begin{array}{c}\text { Number of } \\
\text { Krills }\end{array}$ & $\begin{array}{c}\text { Minimum } \\
\text { Number of } \\
\text { Krill Herd }\end{array}$ & $\begin{array}{c}\text { Maximum } \\
\text { Iteration }\end{array}$ & $\begin{array}{c}\text { Maximum } \\
\text { Induced Speed }\end{array}$ & Dmax \\
\hline 10 & 2 & 200 & 0.01 & 0.005 \\
\hline
\end{tabular}

Table 8 shows the statistical results of training and testing of the proposed ANN model combined with the Krill Herd algorithm (KHA-ANN).

To evaluate the adequacy of the proposed KHA-ANN model, more in detail, the comparative input of Table 8 is based on the following statistical indicators:

$$
M A E=\frac{1}{n} \sum_{i=1}^{n}\left|P_{i}-O_{i}\right| \quad \text { Mean Absolute Error }
$$




$$
\begin{gathered}
M S E=\frac{1}{n} \sum_{i=1}^{n}\left(P_{i}-O_{i}\right)^{2} \quad \text { Mean Squared Error } \\
R M S E=\left[\frac{1}{n} \sum_{i=1}^{n}\left(P_{i}-O_{i}\right)^{2}\right]^{\frac{1}{2}} \quad \text { Root Mean Squared Error } \\
A A E=\frac{\left|\sum_{i=1}^{n} \frac{\left(O_{i}-P_{i}\right)}{O_{i}}\right|}{n} \times 100 \quad \text { Average Absolute Error } \\
E F=1-\frac{\sum_{i=1}^{n}\left(P_{i}-O_{i}\right)^{2}}{\sum_{i=1}^{n}\left(\bar{O}_{i}-O_{i}\right)^{2}} \quad \text { Model Efficiency } \\
V A F=\left[1-\frac{\operatorname{var}\left(O_{i}-P_{i}\right)}{\operatorname{var}\left(O_{i}\right)}\right] \times 100 \quad \text { Variance Account Factor }
\end{gathered}
$$

where $O_{i}$ is an experimental observation and $P_{i}$ is a prediction.

Table 8. Statistical results of training and testing the Krill Herd algorithm (KHA-ANN) model.

\begin{tabular}{cccc}
\hline Statistical Index & $\begin{array}{c}\text { Compressive } \\
\text { Strength }\end{array}$ & Flexural Strength & Tensile Strength \\
\hline MAE & 2.21 & Training & \\
\hline MSE & 10.13 & 0.31 & 0.20 \\
\hline RMSE & 3.18 & 0.20 & 0.08 \\
\hline AAE $\%$ & 0.07 & 0.45 & 0.29 \\
\hline EF & 0.97 & 0.08 & 0.10 \\
\hline VAF \% & 0.98 & 0.97 & 0.96 \\
\hline MAE & & 0.97 & 0.96 \\
\hline MSE & 2.29 & & 0.24 \\
\hline RMSE & 11.72 & 0.37 & 0.14 \\
\hline AAE $\%$ & 3.42 & 0.30 & 0.37 \\
\hline EF & 0.06 & 0.55 & 0.09 \\
\hline VAF $\%$ & 0.97 & 0.07 & 0.94 \\
\hline & 0.97 & 0.97 & 0.94 \\
\hline
\end{tabular}

The results of Table 8 indicate that the proposed KHA-ANN model has an acceptable error in the above-mentioned statistical indicators. Error criteria for training and testing data are calculated using data values in the main range of variables and not in the normal range. The preliminary results indicated that the average value of $R^{2}$ for the compressive, flexural, and tensile strength at the training and testing stage was equal to $0.975,0.972$, and 0.965 , respectively, confirming the high accuracy of the proposed KHA-ANN model with 8-9-8-3 structure. Figure 8 shows the structure of the proposed KHA-ANN model.

Table 9 provides the final weights for both hidden layers estimated by the KHA-ANN model. Using the values of the weights between the different ANN layers, the three output parameters (compressive, flexural, and tensile strength) can be thus determined and predicted. 


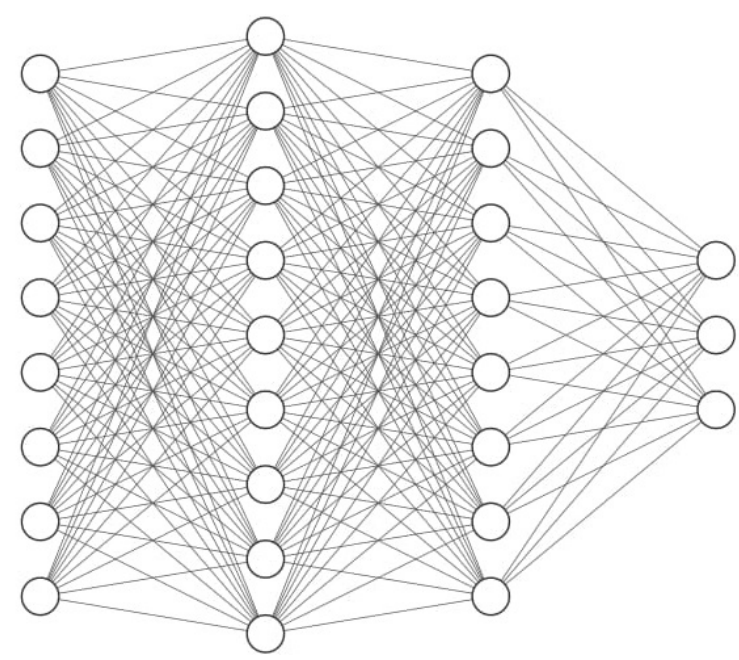

Figure 8. Feed-forward artificial neural network (ANN) with 8-9-8-3 structure.

Table 9. Final weight and bias values for the KHA-ANN model.

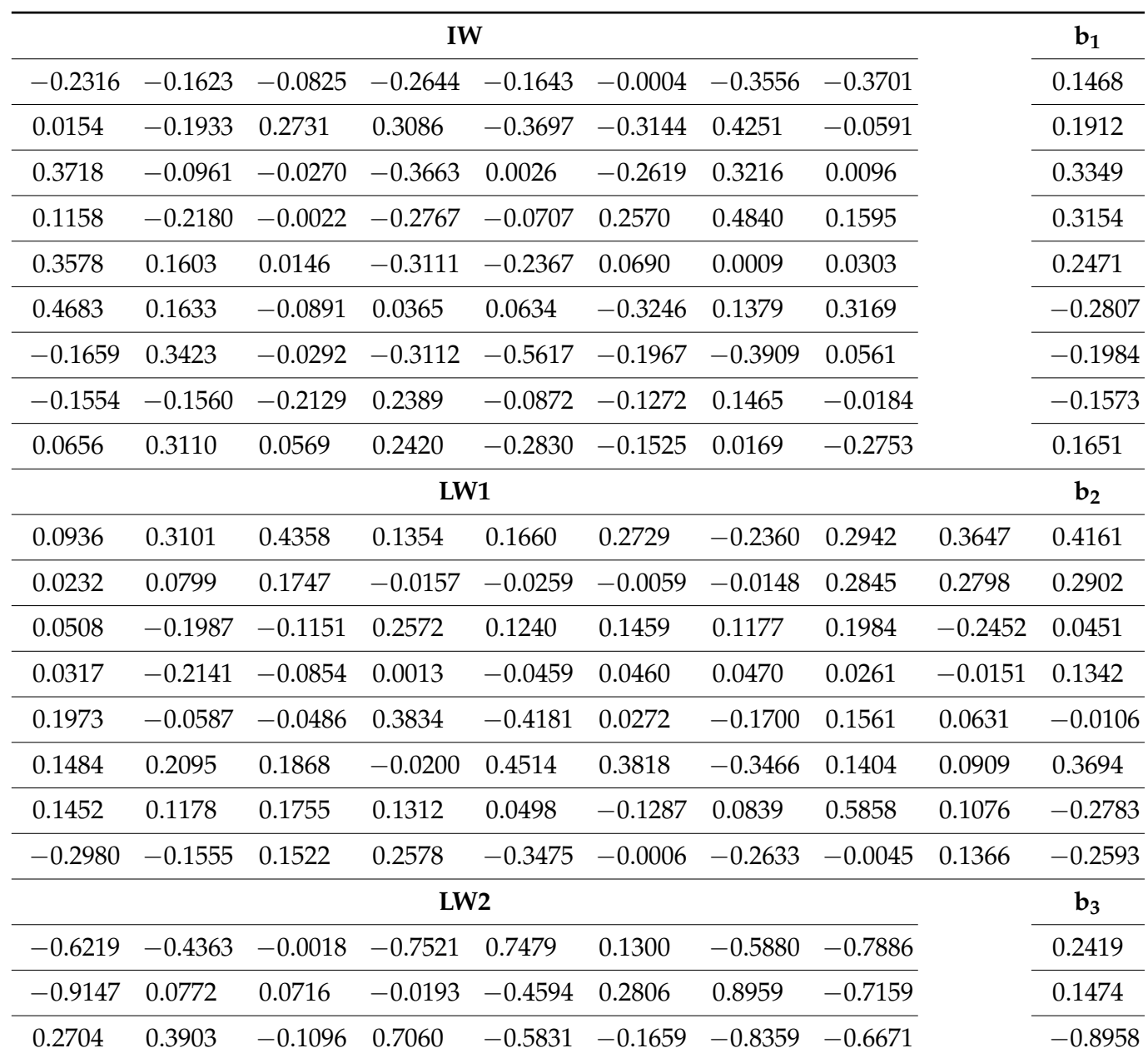

IW: weight values for the input layer; LW1: weight values for the first hidden layer; LW2: weight values for the second hidden layer; $b_{1}$ : bias values for the first hidden layer; $b_{2}$ : bias values for the second hidden layer; $b_{3}$ : bias values for the output layer

\subsection{KHA-ANN Model Validation}

To validate the proposed KHA-ANN model used in this study, a multiple linear regression (MLR) model and a genetic algorithm combined with an ANN (GA-ANN) are 
considered in this study. In an MLR model, two or more independent variables have a major effect on the dependent variable, as shown in the following equation,

$$
y=f\left(x_{1}, x_{2}, \ldots\right) y=a_{0}+a_{1} x_{1}+a_{2} x_{2}+\ldots
$$

where $y$ is a dependent variable; $x_{1}, x_{2}, \ldots$, are independent variables; $a_{1}, a_{2}, \ldots$ are equation coefficients. In this paper, different models of MLR are examined for input and output variables. The most suitable coefficients for the MLR model for each output parameter are given as:

$$
\begin{gathered}
C S=-4.5+19.9 \mathrm{FA}+182.2 \mathrm{GBFS}-3.4 \mathrm{WCP}-0.74 \mathrm{Si}: \mathrm{Al}-73.3 \mathrm{Ca}: \mathrm{Si}-2.31 \mathrm{Ca}: \mathrm{Al}+1.2338 \mathrm{Age} \\
F S=-0.75+1.99 \mathrm{FA}+22.95 \mathrm{GBFS}+0.10 \mathrm{WCP}-0.129 \mathrm{Si}: \mathrm{Al}-8.75 \mathrm{Ca}: \mathrm{Si}-0.294 \mathrm{Ca}: \mathrm{Al}+0.16890 \mathrm{Age} \\
T S=-0.03+0.70 \mathrm{FA}+12.74 \mathrm{GBFS}+0.131 \mathrm{WCP}-0.100 \mathrm{Si}: \mathrm{Al}-4.66 \mathrm{Ca}: \mathrm{Si}-0.211 \mathrm{Ca}: \mathrm{Al}+0.08493 \mathrm{Age}
\end{gathered}
$$

For the second evaluation, a genetic algorithm combined with an ANN (GA-ANN) is concerned, and its characteristics are summarized in Table 10.

Table 10. Characteristics of the genetic algorithm combined with an ANN (GA-ANN).

\begin{tabular}{cccc}
\hline Parameter & Value & Parameter & Value \\
\hline Max generations & 100 & Crossover $(\%)$ & 50 \\
Recombination $(\%)$ & 15 & Crossover method & Single point \\
Lower bound & -1 & Selection mode & 1 \\
Upper bound & +1 & Population size & 150 \\
\hline
\end{tabular}

Table 11 shows the statistical results for input parameters provided by all three investigated models. The results of KHA-ANN, GA-ANN, and MLR models are also shown in Figure 9 for all the three output parameter of CS, TS, FS. The collected results

\begin{tabular}{|c|c|c|c|c|}
\hline Model Name & Statistical Index & $\begin{array}{l}\text { Compressive } \\
\text { Strength }\end{array}$ & Tensile Strength & Flexural Strength \\
\hline \multirow{6}{*}{ KHA-ANN } & MAE & 2.24 & 0.21 & 0.33 \\
\hline & MSE & 10.60 & 0.10 & 0.23 \\
\hline & RMSE & 3.26 & 0.32 & 0.48 \\
\hline & $\mathrm{AAE} \%$ & 0.07 & 0.09 & 0.08 \\
\hline & $\mathrm{EF}$ & 0.97 & 0.96 & 0.97 \\
\hline & VAF \% & 0.97 & 0.96 & 0.97 \\
\hline \multirow{6}{*}{ GA-ANN } & MAE & 2.79 & 0.19 & 0.29 \\
\hline & MSE & 75.74 & 0.15 & 0.44 \\
\hline & RMSE & 8.70 & 0.39 & 0.67 \\
\hline & $\mathrm{AAE} \%$ & 0.07 & 0.07 & 0.06 \\
\hline & EF & 0.82 & 0.93 & 0.94 \\
\hline & VAF \% & 0.82 & 0.93 & 0.94 \\
\hline \multirow{6}{*}{ MLR } & MAE & 6.87 & 0.55 & 0.92 \\
\hline & MSE & 74.21 & 0.47 & 1.37 \\
\hline & RMSE & 8.61 & 0.68 & 1.17 \\
\hline & $\mathrm{AAE} \%$ & 0.21 & 0.25 & 0.24 \\
\hline & $\mathrm{EF}$ & 0.82 & 0.80 & 0.82 \\
\hline & VAF \% & 0.82 & 0.80 & 0.82 \\
\hline
\end{tabular}
indicate that the KHA-ANN model provides more accurate results, compared to the GAANN and MLR models.

Table 11. Statistical results for input parameters. 

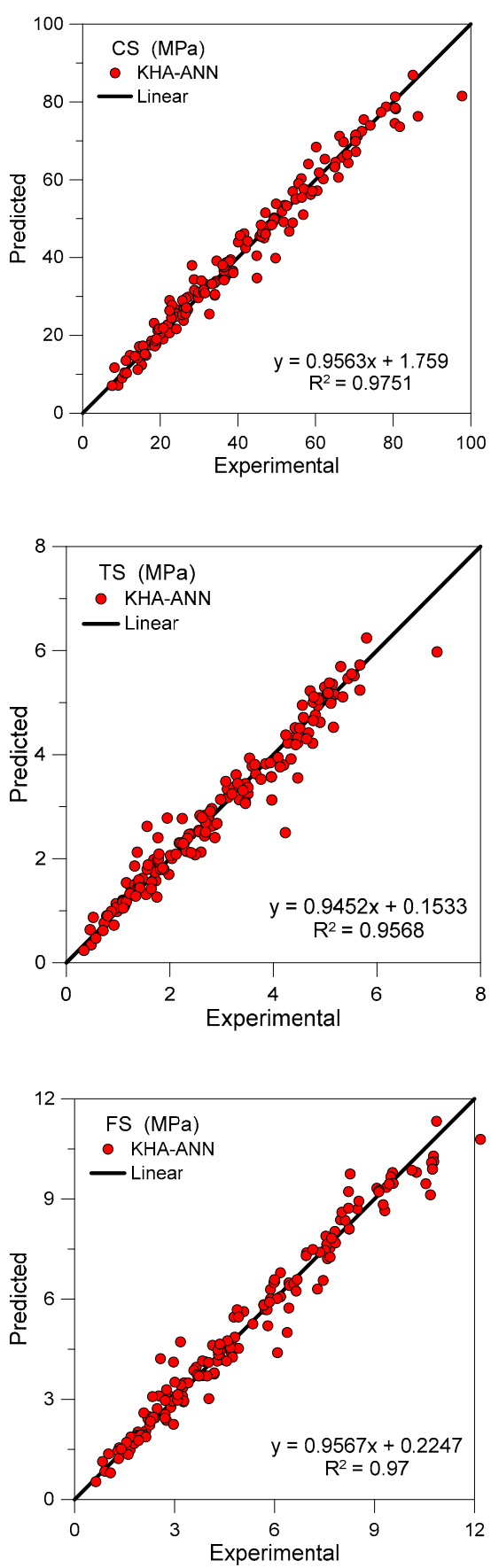
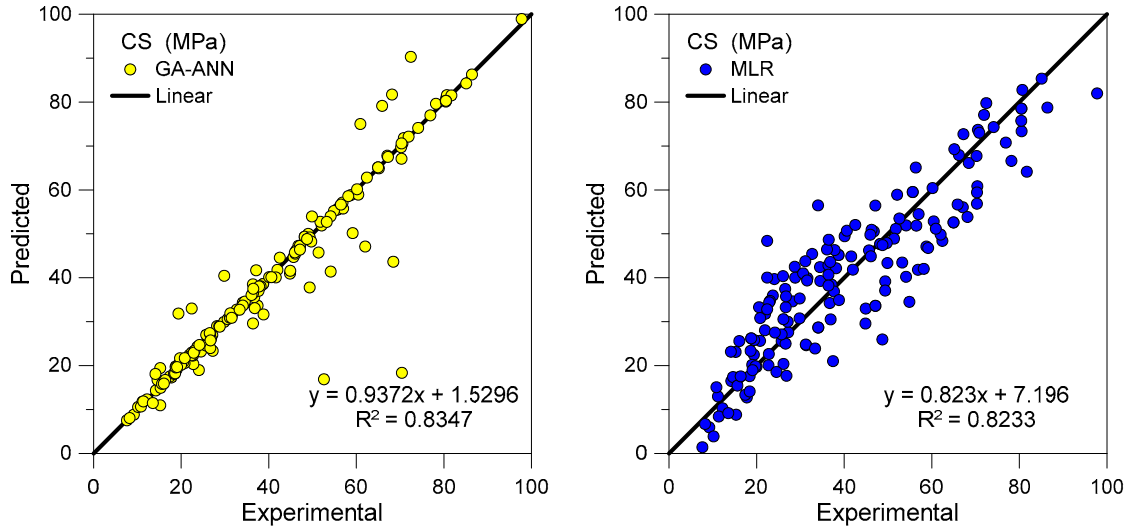

(a)
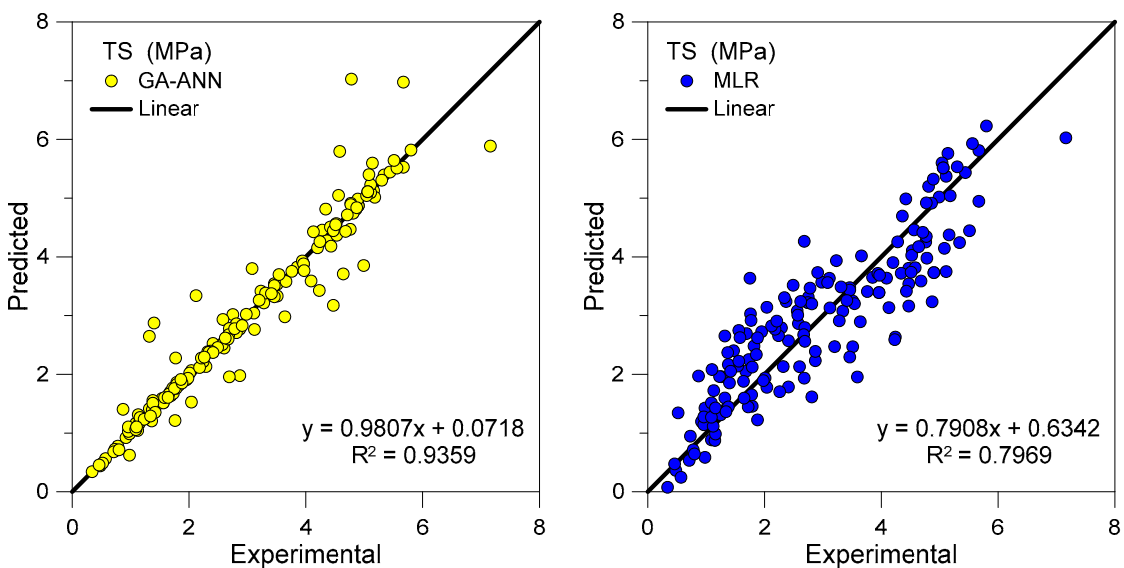

(b)
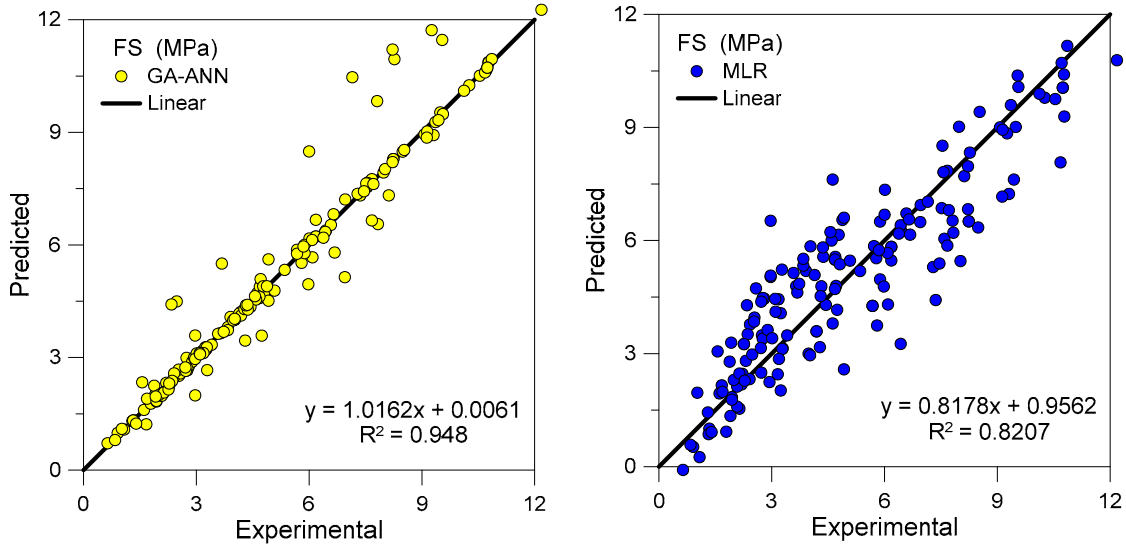

Figure 9. Experimentally observed versus predicted values of (a) compressive strength (CS), (b) tensile strength (TS) and (c) flexural strength (FS), using all the available data.

Given that all three outputs have nonlinear behaviour and are not a function of any fixed trend, the MLR model is found not able to provide reliable results. Its $R^{2}$ value and EF index for all the CS, TS, and FS predictions is in fact characterized by the lowest value, compared to KHA-ANN and GA-ANN models. Meanwhile, the estimated $R^{2}$ value for the GA-ANN model is also not satisfactory. However, the EF index predicted by this model can be seen as more reliable, compared to the MLR model. Nevertheless, the KHA-ANN model provides the most reliable results for both $R^{2}$ and EF indexes, and thus indicating its high potential and accuracy for the purpose of this study. 
Such a confirmation is also acknowledged in Figure 10, where the KHA-ANN model estimates are shown to be more accurate for the ratio of observational to computational values (for all the input parameters), compared to the other two approaches, GA-ANN and MLR.
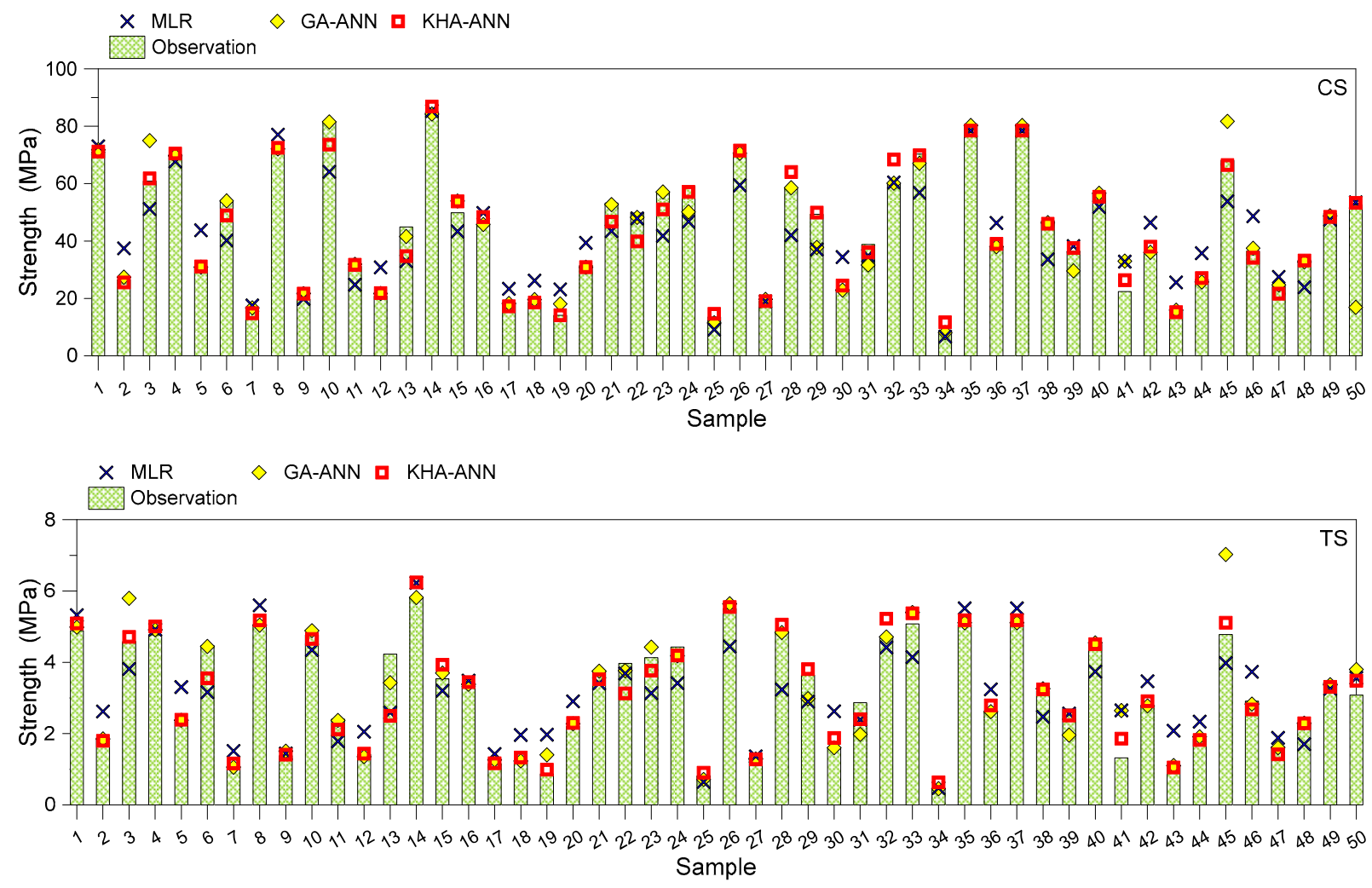

(b)

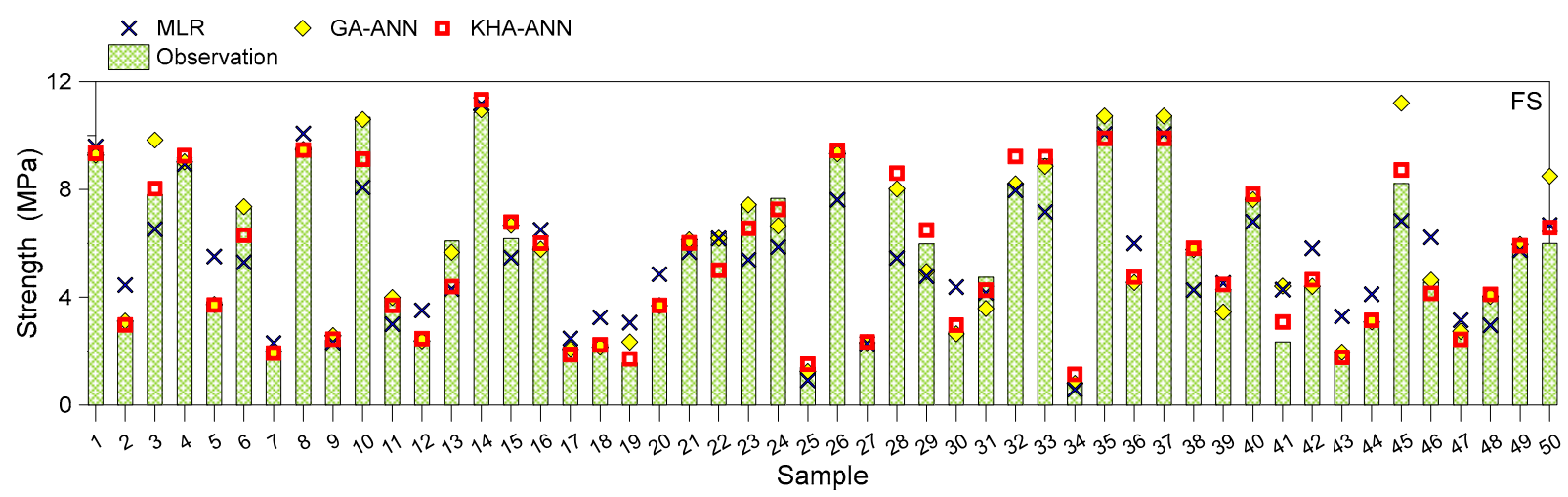

(c)

Figure 10. Observational to computational values for the estimation of (a) CS, (b) TS, and (c) FS parameters (50 out of 168 samples).

\section{Discussion}

The overall analysis of mechanical properties and structural morphology of all alkaliactivated mix categories can be summarized in the following outcomes:

- The results indicate that AAMs with a high volume of GBFS provide the highest mechanical properties. The SEM results also confirm that the alkali activation in this category can produce hydration products in the form of C-S-H, which is the primary reaction product for OPC strength development.

- In the design mixes with high volume FA, by replacing FA with GBFS, a dense gel dominated the AAMs structure, and this results in the further improvement of the observed mechanical properties. The fact is that GBFS has a significant contribution 
to the geopolymerization process in AAMs, thus leading the paste to reach higher mechanical performances.

- An increase in the POFA content was found to reduce the mechanical properties of AAMs. The morphology tests also confirmed that increasing the POFA percentage in AAMs can be associated to the rise in the unreacted silicate and reduced the CS-H product, which significantly affected the CS and microstructure of AAMs. The results show that the ratio of $\mathrm{SiO}_{2}: \mathrm{Al}_{2} \mathrm{O}_{3}$ above 3.5 negatively affects the overall AAMs mechanical properties and microstructure.

- The mechanical parameters of AAMs containing high volume WCP was observed as significantly lower than the other mixes. The ratio of $\mathrm{SiO}_{2}: \mathrm{Al}_{2} \mathrm{O}_{3}$ was relatively high in this category, which negatively affected the forming C-S-H gels in geopolymerization process. The sodium oxide content $(\mathrm{Na} 2 \mathrm{O})$ was also observed at a high ratio $(13.5 \%)$ in the WCP chemical composite, compared to $0.08 \%$ with FA and $0.45 \%$ with GBFS. The negative effect of a high content of silica and low calcium content contributed to the rather poor mechanical performance of these design mixes.

Different amounts of waste were investigated to optimize the mechanical properties and consumption of waste materials in each ternary blended AAMs. Therefore, depending on the availability of the particular waste material and required mechanical properties, a proper design mix can be selected. While GBFS and FA are commonly used in the concrete industry, WCP and POFA have lower interest. This research developed new environmentally-friendly AAMs with WCP, as the main binder, combined by GBFS and FA for various construction applications. The results confirmed that using $50 \%$ to $70 \%$ of WCP in AAMs provided a considerable (36-70 MPa) CS for many building and construction purposes. By exciding this value, the calcium oxide content was reduced and negatively affected the formation of C-S-H gel. The mix prepared with 50\% WCP, 40\% GBFS, and 10\% FA (mix number 40) may represent optimum AAMs in this category, once the consumption of WCP and relatively high CS are needed.

Furthermore, to take advantage of the plentiful amount of POFA as a waste byproduct provided by palm oil industries in several South-East Asian nations, this research proposed ternary blended AAMs containing 50\% to 70\% POFA as the binder mass and different amounts of GBFS and FA. FA is an abundant and cheap waste by-product, and its application in the production of geopolymer and alkali-activated mortar/concrete could lead to sustainable development. On the other hand, the inclusion of GBFS produces secondary hydration that resulted in higher C-S-H formation. This research confirms that the GBFS/FA ratio affects the structural morphology and mechanical properties in AAMs containing high volume POFA. GBFS-rich AAMs had higher mechanical properties and a more dense structure. Depending on the application and the availability of the waste material, each of the AAMs can be selected. For instance, if a high CS is required, the mix number 15 can be considered (around $55 \mathrm{MPa}$ ). On the other hand, if using FA has a high priority, mix number 18 would be recommended, and mix number 10 consumes a high amount of POFA with reasonable CS for many building and construction purposes.

From the developed algorithms to support the mix design, finally, it is also concluded that the KHA-ANN model, on the basis of its final weight and bias values, can be efficiently used to design AAMs with targeted mechanical properties, in which the desired amounts of waste consumption can be optimized on the basis of available local waste materials.

\section{Concluding Remarks}

This study assessed the mechanical properties of ternary blended alkali-activated mortars composed of industrial waste materials, using experimental tests and structural morphology evaluation. To examine the effect of each binder mass percentage on the compressive, tensile and flexural mechanical strength values, 42 engineered AAMs were investigated. By using the available experimental test database, three different models were presented to estimate the mechanical properties of AAMs depending on binder mass constituents. The following provides the main findings of this research: 
1. Test results indicated that the highest mechanical properties were achieved by AAMs with a high volume of GBFS, while the AAMs with a high volume of POFA resulted in the lowest mechanical properties. Furthermore, the average CS, FS, and TS of studied AAMs were predicted in $61.3,7.92$, and $4.33 \mathrm{MPa}$, respectively, which, compared to traditional cement-based mortar, is highly satisfactory from a mechanical point of view, but also characterized by reduced embodied energy and $\mathrm{CO}_{2}$ emission.

2. SEM images revealed that the microstructure of the AAMs containing a high amount of FA was less dense compared to other matrices, due to lack of C-S-H gel formation, where, by the replacement of FA with GBFS, the microstructure of AAMs was enhanced and provided a denser surface. Besides the SEM images have shown that increasing the content of POFA has affected the calcium $(\mathrm{CaO})$ content, as well as the creation of a larger amount of crystalline $\mathrm{Ca}(\mathrm{OH})_{2}$ in hexagonal plate-like structures (unreacted particles/partially reacted matrix) in AAMs with $60 \%$ and $70 \%$ of WCP, both producing poor microstructure and mechanical properties.

3. The XRD pattern of AAMs containing a high volume of FA indicated that the peak intensity corresponds to crystalline quartz $\left(\mathrm{SiO}_{2}\right)$ and mullite $\left(3 \mathrm{Al}_{2} \mathrm{O}_{3} 2 \mathrm{SiO}_{2}\right.$ or $2 \mathrm{Al}_{2} \mathrm{O}_{3}$ $\mathrm{SiO}_{2}$ ) phases, in which by increasing the FA content, the C-S-H gel peak was replaced by a quartz peak where more quartz appeared to be non-reactive. Furthermore, the XRD tests have shown that by replacing GBFS with POFA in AAMs containing 50\% FA, the peak intensity corresponded to the quartz, whereas the peak intensity was dedicated to C-S-H gel in the AAMs with $\%$ POFA ( $50 \%$ FA + $50 \%$ GBFS).

4. FTIR spectra and the FTIR fingerprint zone reveal that by increasing the FA content from $50 \%$ to $70 \%$ in AAMs, the band of C(N)ASH gel product increased from 945.6 to $989.5 \mathrm{~cm}^{-1}$ along with increasing the C-S-H and Si-O band frequency, leading to the less homogenous structure and smaller silicate re-organization, and subsequently negatively affected the mechanical properties of AAMs. Furthermore, the results indicated that GBFS released soluble $\mathrm{Ca}$ that displaced the $\mathrm{Si}$ atoms from $\mathrm{Si}-\mathrm{O}$ bonds, leading to a reduction in the vibrational frequency.

The ANN combined with the metaheuristic Krill Herd algorithm provided satisfactorily results to estimate the mechanical properties of AAMs compared to the ANN combined with the genetic algorithm and multiple linear regression models where statistical indexes such as $R^{2}$ value, EF, and VAF had higher values, indicating a lower error of this model. Furthermore, the Krill Herd algorithm optimization can also be used as a powerful tool in optimizing ANN weights. By using the optimized weight and bias of KHA-ANN, it is possible to design AAMs with targeted mechanical properties and simultaneously manage the consumption of waste materials depending on their availability.

Author Contributions: This research article results from a joint collaboration of the involved authors. G.F.H. developed the experimental tests; M.N. developed the ANN model; I.F. compared the ANN results; C.B. and M.H.B. verified the manuscript structure and supervised the overall research study. All authors have read and agreed to the published version of the manuscript.

Funding: This research work was supported by funding (I.F.) from the Federal State Autonomous Educational Institution of Higher Education South Ural State University (National Research University).

Institutional Review Board Statement: The study did not require ethical approval.

Informed Consent Statement: Not applicable.

Data Availability Statement: Supporting data will be shared upon request.

Conflicts of Interest: The authors declare no conflict of interest.

\section{References}

1. Siddique, R.; Singh, G.; Singh, M. Recycle option for metallurgical by-product (Spent Foundry Sand) in green concrete for sustainable construction. J. Clean. Prod. 2018, 172, 1111-1120. [CrossRef]

2. Turner, L.K.; Collins, F.G. Carbon dioxide equivalent $\left(\mathrm{CO}_{2}-\mathrm{e}\right)$ emissions: A comparison between geopolymer and OPC cement concrete. Constr. Build. Mater. 2013, 43, 125-130. [CrossRef] 
3. Scrivener, K.L.; John, V.M.; Gartner, E.M.; UN Environment. Eco-efficient cements: Potential economically viable solutions for a low- $\mathrm{CO}_{2}$ cement-based materials industry. Cem. Concr. Res. 2018, 114, 2-26. [CrossRef]

4. Katare, V.D.; Madurwar, M.V.; Raut, S. Agro-Industrial Waste as a Cementitious Binder for Sustainable Concrete: An Overview. In Sustainable Waste Management: Policies and Case Studies; Springer International Publishing: Berlin/Heidelberg, Germany, 2019; pp. 683-702.

5. Al-Kutti, W.; Nasir, M.; Johari, M.A.M.; Islam, A.S.; Manda, A.A.; Blaisi, N.I. An overview and experimental study on hybrid binders containing date palm ash, fly ash, OPC and activator composites. Constr. Build. Mater. 2018, 159, 567-577. [CrossRef]

6. Almalkawi, A.T.; Balchandra, A.; Soroushian, P. Potential of Using Industrial Wastes for Production of Geopolymer Binder as Green Construction Materials. Constr. Build. Mater. 2019, 220, 516-524. [CrossRef]

7. Vedrtnam, A.; Bedon, C.; Barluenga, G. Study on the Compressive Behaviour of Sustainable Cement-Based Composites Under One-Hour of Direct Flame Exposure. Sustainability 2020, 12, 10548. [CrossRef]

8. Allalou, S.; Kheribet, R.; Benmounah, A. Effects of calcined halloysite nano-clay on the mechanical properties and micro-structure of low-clinker cement mortar. Case Stud. Constr. Mater. 2019, 10, e00213.

9. Shelote, K.M.; Gavali, H.R.; Bras, A.; Ralegaonkar, R.V. Utilization of Co-Fired Blended Ash and Chopped Basalt Fiber in the Development of Sustainable Mortar. Sustainability 2021, 13, 1247. [CrossRef]

10. Lisuzzo, L.; Cavallaro, G.; Milioto, S.; Lazzara, G. Effects of halloysite content on the thermo-mechanical performances of composite bioplastics. Appl. Clay Sci. 2020, 185, 105416. [CrossRef]

11. Lisuzzo, L.; Hueckel, T.; Cavallaro, G.; Sacanna, S.; Lazzara, G. Pickering Emulsions Based on Wax and Halloysite Nanotubes: An Ecofriendly Protocol for the Treatment of Archeological Woods. ACS Appl. Mater. Interfaces 2021, 13, 1651-1661. [CrossRef]

12. Ogawa, Y.; Uji, K.; Ueno, A.; Kawai, K. Contribution of fly ash to the strength development of mortars cured at different temperatures. Constr. Build. Mater. 2021, 276, 122191. [CrossRef]

13. Kumarappa, D.B.; Peethamparan, S. Stress-strain characteristics and brittleness index of alkali-activated slag and class $C$ fly ash mortars. J. Build. Eng. 2020, 32, 101595. [CrossRef]

14. Islam, A.; Alengaram, U.J.; Jumaat, M.Z.; Bashar, I.I. The development of compressive strength of ground granulated blast furnace slag-palm oil fuel ash-fly ash based geopolymer mortar. Mater. Des. 2014, 56, 833-841. [CrossRef]

15. Ranjbar, N.; Mehrali, M.; Alengaram, U.J.; Metselaar, H.S.C.; Jumaat, M.Z. Compressive strength and microstructural analysis of fly ash/palm oil fuel ash based geopolymer mortar under elevated temperatures. Constr. Build. Mater. 2014, 65, 114-121. [CrossRef]

16. Mohammadhosseini, H.; Lim, N.H.A.S.; Tahir, M.M.; Alyousef, R.; Alabduljabbar, H.; Samadi, M. Enhanced performance of green mortar comprising high volume of ceramic waste in aggressive environments. Constr. Build. Mater. 2019, 212, 607-617. [CrossRef]

17. Samadi, M.; Huseien, G.F.; Mohammadhosseini, H.; Lee, H.S.; Lim, N.H.A.S.; Tahir, M.M.; Alyousef, R. Waste ceramic as low cost and eco-friendly materials in the production of sustainable mortars. J. Clean. Prod. 2020, 266, 121825. [CrossRef]

18. Mohit, M.; Ranjbar, A.; Sharifi, Y. Mechanical and microstructural properties of mortars incorporating ceramic waste powder exposed to the hydrochloric acid solution. Constr. Build. Mater. 2021, 271, 121565. [CrossRef]

19. Li, G.; Liu, S.; Niu, M.; Liu, Q.; Yang, X.; Deng, M. Effect of granulated blast furnace slag on the self-healing capability of mortar incorporating crystalline admixture. Constr. Build. Mater. 2020, 239, 117818. [CrossRef]

20. Awoyera, P.; Adesina, A.; SivaKrishna, A.; Gobinath, R.; Kumar, K.R.; Srinivas, A. Alkali activated binders: Challenges and opportunities. Mater. Today: Proc. 2020, 27, 40-43. [CrossRef]

21. Adesina, A. Properties of Alkali Activated Slag Concrete Incorporating Waste Materials as Aggregate: A Review. Mater. Sci. Forum 2019, 967, 214-220. [CrossRef]

22. Goldaran, R.; Lotfollahi-Yaghin, M.A.; Aminfar, M.H.; Turer, A. Investigation of attenuation and acoustic wave propagation path caused by corrosion for reliability assessment of prestressed pipe monitoring using Acoustic Emission technique. Modares Mech. Eng. 2017, 17, 306-314.

23. ASTM International. C618-15 Standard Specification for Coal Fly Ash and Raw or Calcined Natural Pozzolan for use in Concrete; ASTM International: West Conshohocken, PA, USA, 2015.

24. ASTM International. Cement, Standard Test Method for Compressive Strength of Hydraulic Cement Mortars (Using 2-in or [50-mm] Cube Specimens); ASTM International: West Conshohocken, PA, USA, 2013.

25. ASTM International. C496/C496M-11, Standard Test Method for Splitting Tensile Strength of Cylindrical Concrete Specimens; ASTM International: West Conshohocken, PA, USA, 2004; pp. 469-490.

26. ASTM International. C78/C78M Standard Test Method for Flexural Strength of Concrete (Using Simple Beam with Third-Point Loading); ASTM International: West Conshohocken, PA, USA, 2010.

27. Richardson, I. The calcium silicate hydrates. Cem. Concr. Res. 2008, 38, 137-158. [CrossRef]

28. Kumar, S.; Kumar, R.; Mehrotra, S.P. Influence of granulated blast furnace slag on the reaction, structure and properties of fly ash based geopolymer. J. Mater. Sci. 2010, 45, 607-615. [CrossRef]

29. García-Lodeiro, I.; Fernandez-Jimenez, A.; Palomo, A.; Macphee, D.E. Effect of calcium additions on N-A-S-H cementitious gels. J. Am. Ceram. Soc. 2010, 93, 1934-1940. [CrossRef]

30. Yusuf, M.O.; Johari, M.A.M.; Ahmad, Z.A.; Maslehuddin, M. Evolution of alkaline activated ground blast furnace slag-ultrafine palm oil fuel ash based concrete. Mater. Des. 2014, 55, 387-393. [CrossRef] 
31. Nath, S.; Maitra, S.; Mukherjee, S.; Kumar, S. Microstructural and morphological evolution of fly ash based geopolymers. Constr. Build. Mater. 2016, 111, 758-765. [CrossRef]

32. Nikoo, M.; Hadzima-Nyarko, M.; Nyarko, E.K.; Nikoo, M. Determining the natural frequency of cantilever beams using ANN and heuristic search. Appl. Artif. Intell. 2018, 32, 309-334. [CrossRef]

33. Haykin, S. Neural Networks: A Comprehensive Foundation; Prentice Hall: Upper Saddle River, NJ, USA, 1999.

34. Bishop, C.M. Pattern Recognition and Machine Learning; Springer: New York, NY, USA, 2006.

35. Asteris, P.G.; Nozhati, S.; Nikoo, M.; Cavaleri, L.; Nikoo, M. Krill herd algorithm-based neural network in structural seismic reliability evaluation. Mech. Adv. Mater. Struct. 2018, 26, 1146-1153. [CrossRef]

36. Bolaji, A.L.; Al-Betar, M.A.; Awadallah, M.A.; Khader, A.T.; Abualigah, L.M. A comprehensive review: Krill Herd algorithm (KH) and its applications. Appl. Soft Comput. 2016, 49, 437-446. [CrossRef] 